\title{
What's keeping teens up at night? Reflecting on sleep and technology habits with teens
}

\author{
${\text { Bernd } \text { Ploderer }^{1}(\mathbb{D} \cdot \text { Shannon Rodgers }}^{1}\left[\right.$ [D $\cdot$ Zilu Liang $^{2}(\mathbb{D}$
}

Received: 1 December 2020 / Accepted: 3 December 2021 / Published online: 28 January 2022

(c) The Author(s) 2022

\begin{abstract}
Sleep studies suggest that exams, jobs, and technologies keep teens up at night, but little research exists to engage teens in reflecting on their own sleep. We designed a set of cards and a web-based app 'SleepBeta' to support reflection by inviting teens to ask questions, explore, track, and experiment with sleep and related technology and lifestyle habits. Through card sorting, we invited teens to identify technology and lifestyle habits they wished to track. SleepBeta let teens track various habits and sleep whilst visualizing interrelationships between these data. Twelve teens and 11 parents participated in interviews before and after a 3-week field trial of SleepBeta. Our findings highlighted four distinct modes of reflection: reflection in preparation, reflection in action, reflection upon revisiting data, and reflection through social interaction. We discuss how our findings provide sensitizing concepts that reframe reflection from a post hoc activity with personal data, to an ongoing process that starts before technologies are used to generate data. We highlight design opportunities for scaffolding reflection in preparation, and we reflect on design choices that give teens control over their data.
\end{abstract}

Keywords Teens $\cdot$ Adolescents $\cdot$ Reflection $\cdot$ Sleep $\cdot$ Self-tracking $\cdot$ Personal informatics $\cdot$ Personal data $\cdot$ Quantified Self

\section{Introduction}

The interactions between teens and parents around sleep and digital technology can be challenging. In terms of sleep, there is a concern that teens are not getting enough of it, which can negatively affect the behaviour, feelings, and social relationships of teens, as well as their academic performance [1-4]. Sleep needs and sleep patterns are naturally changing during adolescence, so that teens will want to go to bed later at night and get up later in the morning [2]. However, school starting times remain the same, which can create tension between teens and parents. Beyond that, sleep is also impacted by lifestyle factors, e.g. stress at school, part-time jobs, and caffeine consumption, which can add to the perception that teens do not get enough sleep [1].

Personal and ubiquitous technologies can further complicate matters. Smartphones can be a cause of tension

Bernd Ploderer

b.ploderer@qut.edu.au

1 School of Computer Science, Queensland University of Technology (QUT), Brisbane, Australia

2 Ubiquitous and Personal Computing Laboratory, Kyoto University of Advanced Science (KUAS), Kyoto, Japan between teens and parents, with concerns of phone overuse and diminishing the time and quality of sleep that teens get, especially when used during bedtime $[1,5]$. Sleep studies also suggest that video games, music, and video streaming can keep teens up at night and reduce the amount of sleep they get $[3,4,6]$.

Despite these concerns, however, there is limited research on engaging teens themselves to reflect on their own sleep and the potential impact of technology. Off the shelf technology like smartwatches and fitness trackers support sleeptracking, but they provide little guidance on what habits to track, what questions to ask of the data, and how sleep data might relate to technology use [7]. Health research relies on teens as research subjects to providing data for large cohort studies into sleep [1-4], but neither teens nor parents are engaged in these studies to reflect on their own data and experiences. HCI research, on the other hand, often promotes engagement through a Quantified Self approach where teens or entire families are invited to track and quantify their exercise and sleep [8-10]. However, there is an inherent assumption in self-tracking research that the data will simply lead to reflection and action, with little consideration on how to initiate and support reflection. 
Hence, the aim of this research was to explore how we might engage teens to reflect on their sleep and related lifestyle and technology habits. To support such reflection, we created various resources for better sleep, aka 'SleepBeta' (illustrated in Fig. 1). SleepBeta contains a card-set that invites teens to reflect on current habits and to ask personally relevant questions, e.g. do I get less sleep on days that I play video games? We also designed a web-based 'SleepBeta app' for teens to track and reflect on relevant lifestyle and technology habits through a diary on their mobile phone (see Fig. 1). The app integrates sleep data from a fitness tracking device, and it visualises sleep data and emerging correlations with diary data to let teens reflect on possible relationships, e.g. if they indeed get less sleep on days that they play video games. Finally, we invited parents to discuss sleep with their teenage children to encourage reflection.

Based on interviews with 12 teens and 11 parents during a 3-week field study of SleepBeta we found that reflection upon revisiting data from SleepBeta was helpful to explore relationships between sleep and lifestyle factors, i.e. exercise, and to reassure teens that their sleep patterns were normal. However, we also observed three other modes of reflection that were less reliant on the available of personal data. Reflection in preparation occurred when teens reflected on their current experiences and questions, to prepare for self-tracking. Reflection in action highlighted the importance of taking actions to change habits in order to gain new insights. Finally, reflection through social interaction with family members and peers was critical to reflect on sleep data and experiences.

Through these findings, this paper seeks to offer three contributions to our understanding of reflection with personal and ubiquitous technologies: Firstly, we discuss how the self-tracking reflections of teens differ from the reflections of adults in terms of concerns around technologies used at night, questions about sleep quality, and their underlying motivations for sleep-tracking. Secondly, whilst current notions of reflection through self-tracking focus on reflection once data has been collected [11, 12], our findings on reflection in preparation highlight that reflection can precede data collection, provided scaffolds (like cards) are available. Finally, our findings on reflection through social interaction highlight both the importance of dialogue for reflection as well as privacy challenges. Based on these observations, we reflect on our design choices and discuss design opportunities to better support reflection during the various stages of self-tracking.

\section{Related work}

Our study connects multiple research areas. We begin by discussing health research on the sleep of teens, followed by HCI research on sleep tracking and reflection.

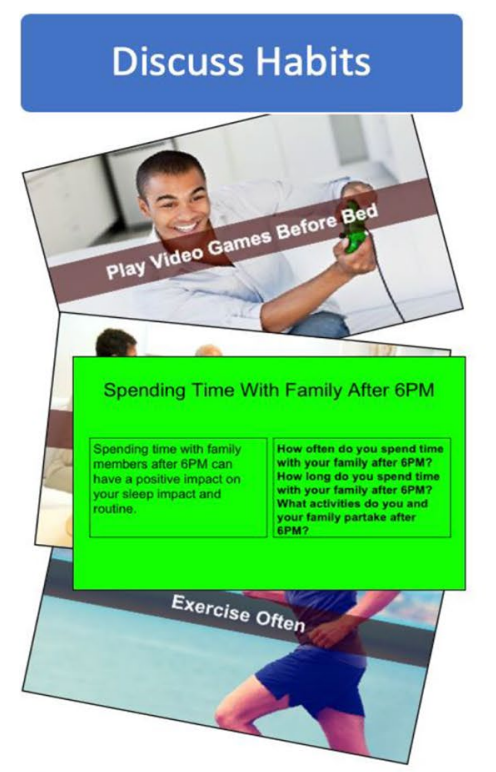

SleepBeta Cards
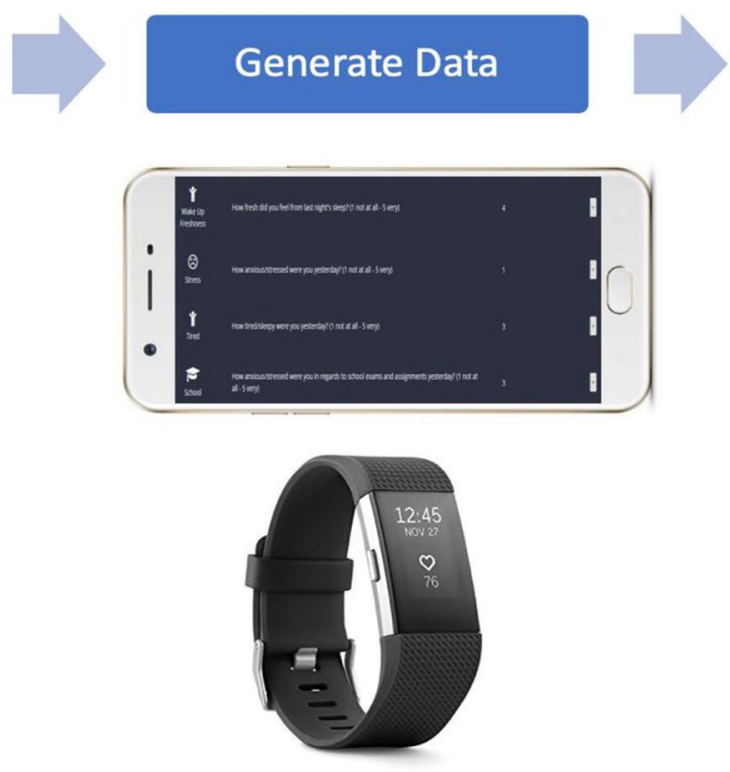

SleepBeta Diary

\& Fitness Tracker

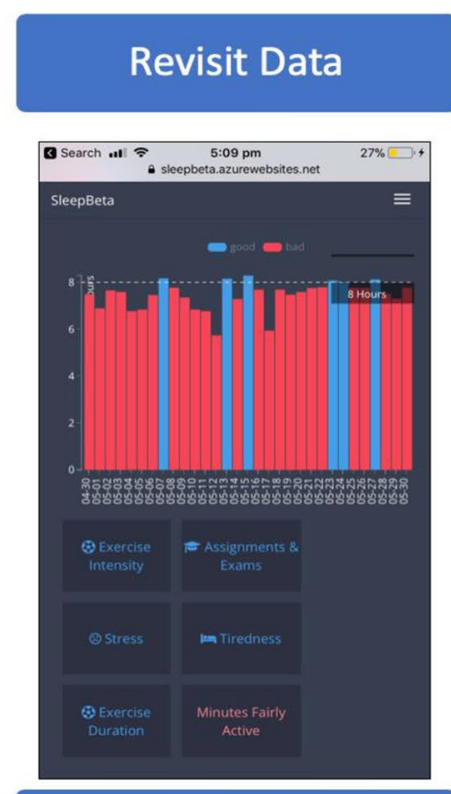

SleepBeta Dashboard
Fig. 1 To reflect on sleep with teens, we designed SleepBeta: (1) a set of cards about technologies and lifestyle factors invites reflection on possible impacts on sleep. (2) A diary app allows teens to track per- sonally relevant factors and a fitness tracker generates sleep and physical activity data. (3) A dashboard visualises sleep data and correlations with factors tracked to support reflection upon revisiting data 


\subsection{What is keeping teens up at night?}

Sleep studies suggest that what is keeping teens up at night is a combination of biological factors and modifiable lifestyle factors, including technology habits. In terms of biological factors, sleep studies show that teens naturally want to go to bed and wake up later. This is because of hormonal changes during puberty that delay the release of melatonin later at night than during earlier childhood, which affects the daily (circadian) rhythm of sleep propensity [2]. Furthermore, teens can and want to stay awake for longer due to maturational changes to the brain [13]. Hence, to allow for later bedtime and sufficient sleep, some countries have delayed school time, which has led to greater student alertness and wellbeing [14].

The change in sleep patterns can be further exacerbated by lifestyle factors, including technology habits. A main inspiration for this research has been the study by Harbard et al. [1], which examined the relationship between sleep and 26 pre-bedtime behaviours. Based on a 3-week study with 146 teens between the ages of 15 and 17 years, it was found that the following behaviours showed statistically significant correlations with sleep: playing video games and late-night snacking were associated with later bedtime and less sleep during school time. Social media use was associated with longer time take to initiate sleep, but this finding was only statistically significant during vacation time. Conversely, spending time with family in the evening was associated with earlier bedtime and longer sleep, possibly because these teens were subject to stricter rules set by their parents or because spending time with family let to more established routines. Other studies point to binge viewing of TV and video streaming [6] and social media use [15] as threats to sleep.

There are several reasons why digital technologies are deemed a threat to sleep: time spent using technologies means less time for sleep (time displacement); stimulation from video games or other 'exciting' technologies can increase heart rate and delay the onset of sleep; the blue light emitted by screen-based technologies can also affect the circadian rhythm and delay the onset of sleep $[2,16,17]$.

Recommendations for parents suggest the following strategies to help teens get the recommended $8-10 \mathrm{~h}$ of sleep $[13,16,18]$ : establishing healthy digital technology habits as well as healthy bedtime habits with their children, being a role model that prioritises sleep, communicating about the importance of sleep for their wellbeing, and developing appropriate technology and sleep rules to guide children and to help them understand the after-effects of failing to follow rules (e.g. being tired and low on energy the next day).

Taken together, these studies of teens are helpful to understand patterns of sleep and technology habits and to establish guidelines for parents. However, within these studies, there appears to be a lack of engagement with teens to reflect on their priorities and if these large-scale patterns might also apply to their unique circumstances.

\subsection{Engaging teens with sleep}

HCI research on sleep typically either focuses on understanding current sleep habits or on tracking sleep through mobile and wearable devices. In terms of understanding sleep habits, a recent study by Davis et al. [5] highlighted that parents and teens recognise that they use the phone too much and the impact it can have on quality time with the family, but also that the phone may delay their bedtime. Blackwell et al. [19] similarly found that the phone is the cause of tension, as well that teens think that parents overestimate how much time they spend on the phone at night. Yardi, Bruckman [20] observed that parents of younger teens enforce rules about limiting digital technologies used during the evening more strictly than for older teens. Hiniker et al. [21] found that teens are less like to follow rules that ban technologies in certain contexts only, e.g. at the dinner table or after bedtime. Looking at adult couples rather than teens, Salmela et al. [22] highlight that phone use in bed is widespread, and that it not only disrupted sleep patterns but that it also affected the attention given to partners and intimate interactions.

In terms of sleep-tracking, there is HCI research under the umbrellas of self-tracking, Quantified Self, and personal informatics. Self-tracking describes practices relating to the collection and interpretation of personal data through digital technologies [7]. Self-tracking is closely associated with the Quantified Self, a community of early adopters of self-tracking technologies. In HCI, self-tracking is also often referred to as 'personal informatics' [11], which highlights the role of technologies, or as 'lived informatics' [23], which emphasises how people integrate self-tracking with other everyday life practices. There are several motivations for self-tracking that are also relevant to sleep: curiosity in the data, goal-driven tracking to experiment, diagnose problems and improve wellbeing; documenting activities rather than change them; and a fetish for new technology [23, 24].

Self-tracking studies with teens highlight particularly social concerns. In school settings, self-tracking with teens has highlighted identity and authority as key concerns, with self-tracking data providing a reference point for teens for their still-forming personal identities [9]. Materialist concerns, i.e. the appearance of self-tracking devices as well as assumptions about the wealth associated with technology, are also a social concern for teens at school [25]. In family settings, self-tracking provides teens and parents with opportunities not only to share and compare data, but also to identify ripple effects to understand how the behaviour of one family member affects others [10]. However, in families 
where only children track exercise and sleep, there is a risk that parents monitoring their children's data undermine opportunities for teens to voluntarily share information and to build trust between teens and parents [8].

Sleep-tracking is a common focus of HCI research, enabled by various mobile phone apps and wearable fitness trackers that allow people to generate sleep data in their own homes. Whilst it is relatively easy to generate sleep data, making sense of the data, identifying reasons for possible sleep problems, and taking steps to improve one's sleep remain a challenge [26-28]. There are several reasons for this. First, sleep (unlike physical activity) is an unconscious, passive activity. Hence, it is difficult to verify tracking data with personal experience. Second, the way consumer devices collect and process sleep data remains a black box for users due to proprietary algorithms developed by vendors [29], which adds to the difficulties that people have in verifying their data. Third, it is difficult to define what constitutes good sleep. Consumer devices provide insight into sleep length and sleep interruptions overnight. Accurate measurement of sleep stages (i.e. deep sleep, light sleep, and REM sleep) would require clinical sleep measurement through multiple metrics (including EEG). However, as pointed out by Ravichandran et al. [26], information about sleep stages and doubts about the accuracy of such information only add to the confusion about what constitutes good sleep. Finally, as highlighted in the previous section, sleep can be influenced by a range of factors, e.g. what we eat and do during the day, how we feel, technology use before bedtime, and the sleep environment (temperature, noise). Popular consumer devices like Fitbit, however, provide no way of examining possible relationships between these factors and sleep outcomes. Whilst more recent designs of sleep-tracking systems allow people to explore connections between sleep and other data [30-32], there appears to be an inherent assumption that these data and interrelationships will provide people with answers about their sleep.

What is needed, we contend, are ways to help teens figure out what questions to ask in the first place, what data to collect, and what reflections and insights might be possible through personal data. To achieve this, we need to bridge the knowledge from the aforementioned large-scale sleep studies, HCI's knowledge to design tools and methods to collect and visualise data, but also knowledge on how to promote and scaffold reflection through technology design.

\subsection{Reflecting with data and technology}

In a broad sense, reflection of the mind means to turn one's thoughts back on some issue [33]. In a learning context [34], reflection is often described as a cycle, where individuals turn back to a particular learning experience to develop abstract ideas and strategies. The cycle continues by applying such strategies to similar situations in the future and by continuing to reflect on the outcomes. The notion of double-loop learning [35] (sometimes also described as critical reflection [36]) suggests the presence of a second cycle, where learners reflect not just on their strategies and actions, but also on their perspectives - the assumptions and their understanding of the surrounding world on which their actions and decisions depend.

There is a long tradition in HCI to design for reflection. In a seminal paper on reflective design, Sengers et al. [37] argue for the importance of reflection in technology design practices for both designers and users in order to bring unconscious aspects of our experience to the fore and make them available for conscious choice. Their paper [37] highlights several key principles that resonate strongly with the broad aim of this research: to support users in reflecting on their own lives to enhance their freedoms; to integrate reflection with action to make it central to a user's experience, and dialogue between designers and users through technology to enhance reflection. Furthermore, reflective design offers strategies to encourage reflection by users that align closely with our work, in particular, providing interpretive flexibility to allow collective sensemaking between users, technology, and designers, and designing technology as a probe that provides researchers with new insight, in our case the sleep, lifestyle, and technology practices of teens.

In the context of self-tracking with digital devices [11], reflection refers to turning one's thoughts on objective data that a person has collected, rather than subjective experiences. Whilst reflection is central to self-tracking, we concur with Baumer [38], p. 586] that 'despite its central importance, work on personal informatics provides relatively little detailed explication of what actually constitutes reflection' on personal data. According to Li's stage-based model of personal informatics [11], reflection is the result of a process that starts with preparation, followed by data collection and integration, which enables reflection and action. Common insights from reflecting on personal data include recalling experiences, identifying valuable detail in the data, comparisons, and trends [39]. Objects and physical instantiations of data can aid reflection, because they evoke concrete memories and experiences in everyday life contexts [40, 41]. Refinements of the personal informatics model highlight self-tracking is not necessarily a linear process — instead data collection, integration, and reflection are iterative [12] and reflection occurs not only at the end but also whilst data is collected and integrated [24, 42]. The problem with this line of research, however, is that these observations are often based on observations with experienced and passionate self-trackers, including Quantified Self members [24, 42] or researchers [43]. These self-trackers have the means and expertise to inspect and analyse their data to identify problems and pursue goals, but their means and outcomes 
do not necessarily apply to other cohorts like teens. Selftracking and reflection can be made more accessible to nonexperts through automated tracking [44, 45], user modelling [46], and predictions [47], but these technology-driven approaches can also diminish opportunities for people to engage with data and to reflect upon it $[42,46]$.

Baumer et al. [38, 48] offer useful reflections on what constitutes reflection and how it might be studied. Firstly, they see reflection as a process of inquiry that is conscious and intentional and ultimately involves transformation. Secondly, reflection is not always a smooth journey to enlightenment; in fact, reflection is often precipitated by various types of breakdowns. Attempts to repair breakdowns require individuals to explicate knowledge that would otherwise be taken for granted. Breakdowns in technology provide an opportunity to reflect on their functionality and the meaning of the data that they generate [38]. Similarly, reflection on personal data can also turn to rumination, where negative thoughts and emotions inhibit personal development [49]. Finally, HCI often sees reflection as an individual endeavour, which represents an opportunity to design for reflection as a social process [48, 50, 51]. Viewed this way, reflection becomes an inquiry where people engage in a dialogue to articulate, examine, and evaluate each other's interpretations.

The work of Fleck and Fitzpatrick [52] highlights several levels of reflection. Based on a review of literature across HCI and education, they propose the following: (1) reflective description, which involves revisiting data or events and developing explanations; (2) dialogic reflection, where relationships between different pieces of experience or data are related and interpreted; (3) transformative reflection, where revisiting data or experiences leads people to change their assumptions and practices; and (4) critical reflection that goes beyond oneself to examine wider implications like social, ethical, and environmental implications. These levels are useful, because they highlight different activities and outcomes in terms of change, both personal change and change that is reflective of the wider environment. The work also highlights that reflection does not necessarily lead to any change, and it also acknowledges the absence of reflection, e.g. when people merely revisit data or events, but without attempting to explain or interpret them.

Schön's discussion of reflection-in-action [53] highlights that reflection is not necessarily a post hoc activity where a person thinks back about something that they have done, but that reflection is happening at the time of doing. In Schön's work, we see that reflection is not separate from action: 'In reflection-in-action, doing and thinking are complementary. Doing extends thinking in the tests, moves, and experimental action, and reflection feeds on doing and its results. Each feeds the other, and each sets boundaries for the other.' [53]. Taking Schön's ideas further, Slovak et al. [54] highlight that reflection-in-action cannot be taught to people but that it requires learning by doing. This involves a learner who actively constructs expertise in reflection-in-action. It also requires scaffolding, e.g. through an expert (a coach) who provides opportunities for learning by doing in a safe environment where learners can make failures without adverse effects. Scaffolding from the expert is also required to support the learner in grasping the significance of particular experiences and data and to help them transform these experiences into learning.

In summary, these studies show that reflection is not a natural outcome of collecting and revisiting data through personal informatics systems, but instead an ongoing process of inquiry. An inquiry into a topic such as sleep and technology habits requires scaffolding so that teens can learn how to construct insight from experiences and data. Scaffolding can come from technology design as well as from social interaction with people who provide expertise.

\section{SleepBeta cards and app design}

SleepBeta was designed to engage teens in reflecting about their sleep. Inspired by the need to work with teens and to create tools to scaffold reflection, we created a set of cards to prompt questions about sleep and a web-based app to generate and revisit personal sleep data for reflection.

We created a set of 25 cards for a card-sorting activity with teens to encourage reflection on technologies and lifestyle factors which may influence their sleep. As listed in Table 1, the cards were based on 5 technology factors and 12 lifestyle factors identified in prior sleep research to influence sleep [1, 6, 15, 17, 55-58]. Eight cards were added to ask about sleep environment and subjective experience (e.g. 'wakeup freshness', 'wake up early') [59-64]. As illustrated in Fig. 1, the front of the card showed an image and the factor, e.g. 'Using the Phone Before Bed'. The back of the card provided explanations about the potential impact of this factor, e.g. 'Exposure to too much unnatural light will impact parts of the brain that make us feel sleepy'. Furthermore, the back of the cards listed potential questions to explore for teens: 'How long did you spend on your phone last night after 6PM?' The background colour provided an indication of the potential impact, e.g. with red indicating a potential negative influence on sleep (e.g. for phone use), and green indicating potential positive influence (e.g. for time spent with family after $6 \mathrm{pm}$ ) [1]. Appendix 1 shows the complete SleepBeta card set.

The SleepBeta app has been designed to encourage teens to reflect on possible relationships between their sleep patterns and their lifestyle and technology habits. The idea of showing relationships between sleep and other lifestyle factors has been inspired by the designs of 
Table 1 Technology, lifestyle, and sleep factors discussed through SleepBeta cards (see Appendix 1 for full card set)

\begin{tabular}{lll}
\hline Technology & Lifestyle & Sleep \\
\hline Listen to music before bed & Anxious/stressed & Cleanliness of bedroom \\
Play video games before bed & Assignments and examination & Light in bedroom before sleep \\
Texting/using your phone before bed & Drink alcohol & Noise in bedroom before sleep \\
Use social media & Drink caffeine (coffee, energy drinks) & Stay up later on weekends \\
Watch TV at night & Exercise often & Take naps \\
& Late night snacking & Temperature in bedroom \\
& Medication & Wake up early \\
& Mood & Wake up freshness \\
& Part-time job & Spending time with family after $6 \mathrm{pm}$ \\
& Spending time with friends after $6 \mathrm{pm}$ & Write a diary/journal \\
\hline
\end{tabular}

Lullaby, SleepTight, and SleepExplorer [30-32]. However, for the teenage audience, we kept the information simple, and we sought to automate data collection as much as possible.

The SleepBeta app collected and integrated data from several sources. Participants received a Fitbit Charge HR device to track sleep and exercise data. Whilst not classified as a medical-grade sleep tracker, Fitbit Charge HR shows good agreement with gold-standard laboratory polysomnography (PSG) in measuring total sleep time and sleep efficiency for adolescents $[65,66]$. The participants' Fitbit data was automatically imported into the SleepBeta app. Furthermore, SleepBeta offered a diary for teens to manually track relevant technology and lifestyle factors. The diary reflected the set of 20 cards. Based on the cards chosen during the card-sorting activity, a personalised diary was set up for each teen. Participants were invited to fill in their diary of each morning by selecting responses from dropdown fields, e.g. 'How stressed were you yesterday? (1 not at all-5 very)'.

SleepBeta visualised both the sleep data and correlations with technology and lifestyle factors tracked through the diary and Fitbit. As illustrated in Fig. 2, bar charts showed the hours asleep each night over. Blue bars signified nights when the participant had enough sleep (8-10 h), whereas red indicated nights when she had less sleep than recommended for a person her age [18, 67]. The two dashed lines indicate the recommended sleep hours $(8-10 \mathrm{~h})$ for teens by the National Sleep Foundation of the USA [67]. Teens could also inspect the time awake each night and their sleep efficiency. The boxes on the bottom of the screen indicated a correlation between the hours asleep each night and lifestyle factors. This was based on Spearman correlation coefficients calculated for each pair of variables, with missing values pair-wisely removed. Participants could access short explanations of these correlations by tapping on the box, e.g. 'Your hours asleep are worse when you are more sedentary'.

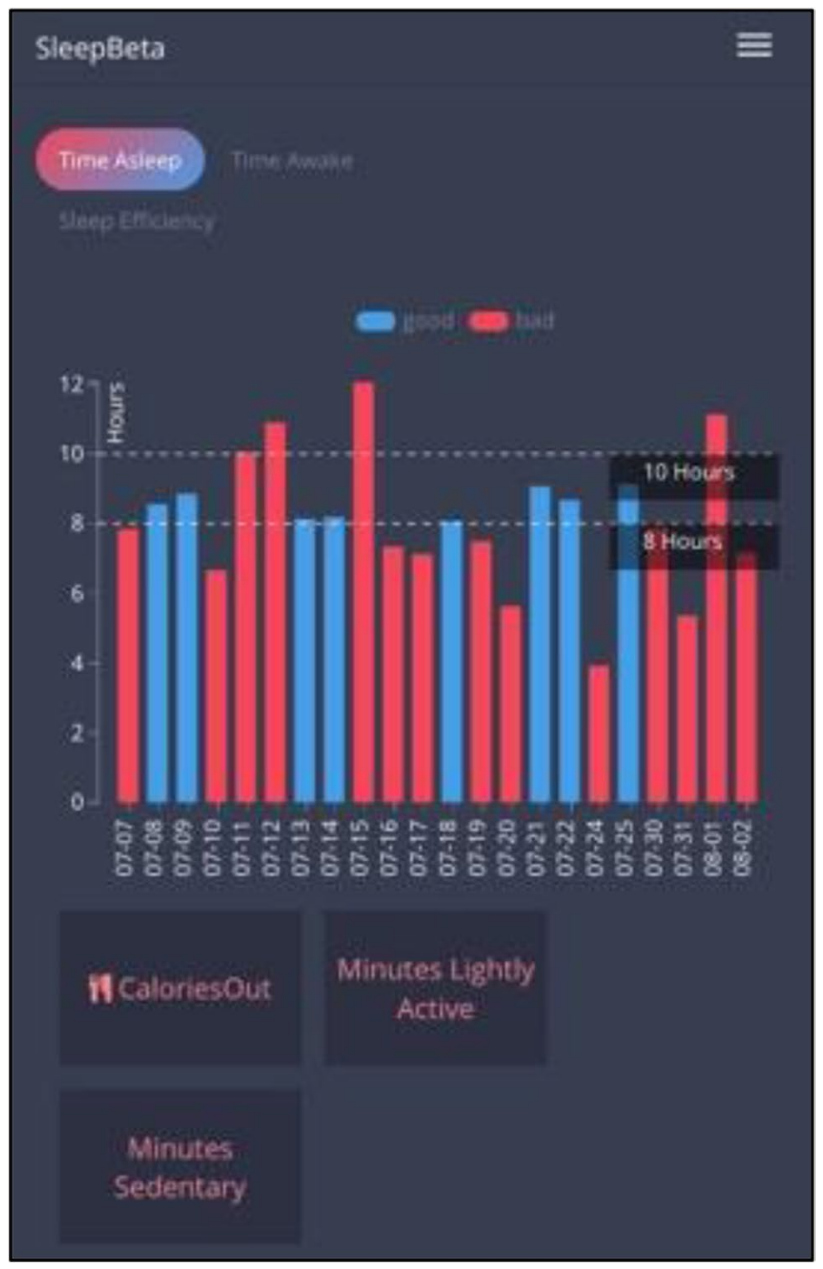

Fig. 2 Screenshot of SleepBeta for T8, showing the hours slept each night for the last 2 weeks. The boxes on the bottom highlight a correlation between length of sleep and calories burned, minutes lightly active, and minutes sedentary. The red colour indicates a negative correlation, e.g. suggesting on days when T8 was more sedentary she also slept less 
SleepBeta was designed iteratively by the research team together with 4 teens, who trialled SleepBeta during a 2 -week pilot study. This pilot study helped us to improve the usability of the app design and to clarify the content presented on the card set, i.e. to ensure that contents between cards and app were aligned. The trial study also helped us to refine our study design; most notably we decided to include parents in the study design to encourage ongoing interaction about sleep and technology habits within the teen's family.

\section{Field study design}

The aim of this research was to explore how we can engage and support teens in reflecting on their sleep habits. We were particularly interested in understanding (1) the role of cards to prepare relevant questions, (2) insights from personal data from SleepBeta, and (3) the sociality of reflection through interactions with parents and peers. This study was approved by the QUT Human Research Ethics Committee (approval number 1600000582).

\subsection{Positionality statement}

Since this article focuses on reflection, we start by reflecting on our own backgrounds and perspectives in this study [68]. Author 1 is a HCI researcher with an ongoing interest in personal informatics and sleep-tracking. As founder and organiser of a local Quantified Self meetup group, author 1 has heard many inspiring stories of how personal data can be meaningful and helpful for people to better understand and control their health and wellbeing. At the same time, author 1 feels reluctant to track his own lifestyle as he shares concerns with critical scholars of self-tracking [7, 69] about privacy, fetish for devices, healthism, and the onus on individual rather than community action. He supervised the data collection and led the analysis and writing of this article. Author 2 is currently a $\mathrm{PhD}$ student in $\mathrm{HCI}$ interested in mental health and sleep. Author 2 conducted the data collection with several participants recruited through her former high school, and she conducted an initial analysis. Author 3 is a data scientist working in the domain of wearable health technology. She developed SleepBeta and has been interested to explore it with teens. All authors worked together on the study design and the revisions of the article before submission.

\subsection{Participants}

The field study was conducted in Brisbane, Australia, with 12 teens who used SleepBeta over a period of at least 3 weeks. At least 2 of these weeks were during the school term to examine possible relationships between stress and sleep. Participants were recruited through two avenues to recruit a diverse group of teens: we recruited 8 teens who were interested in learning more about their sleep through personal contacts of the second author with teens from the public high school she had attended. With the help of a sleep physician, we recruited 4 teens with a diagnosed sleep problem, who wanted to better understand and control their sleep problem. As shown in Table 2, the cohort involved 6 female teens and 6 male teens between the ages of 13 and 17 .

\subsection{Data collection and analysis}

All 12 teens were invited to reflect on their sleep by trialling SleepBeta for 3 weeks, combined with interviews at the start and end of the trial study. These interviews took place in the homes of the participants and lasted between 25 and $45 \mathrm{~min}$. The first interview focussed on lifestyle and sleep habits of our participants. We visited the teens' bedrooms to learn about how their sleep environment may influence their sleep. Then we invited participants to select SleepBeta cards that they thought may be relevant to their sleep habits. Based on the cards chosen, we inquired into the participants' sleep habits and their concerns and experiences about the possible impacts of technology and lifestyle factors on their sleep. We then used the cards selected by teens to set up their SleepBeta diary. Table 2 shows the factors selected by each teen. The interview ended by showing teens how to use Fitbit and SleepBeta.

All participants were invited to trial SleepBeta for 3 weeks. They received a Fitbit Charge HR device to track their sleep patterns and physical activity. All participants were given access to SleepBeta app via their personal mobile phones to generate and revisit personal data. Participants were asked to fill in their SleepBeta diary morning to reflect on the previous day and night's sleep. Furthermore, we encouraged them to revisit their sleep data and to look for emerging correlations with technology and lifestyle factors presented through the visualizations in the app.

The second interview was conducted after 3-5 weeks. This interview focused on the experiences of teens in tracking and reflecting on their sleep habits. We asked participants to show us their data on SleepBeta and to tell us about their sleep and their lifestyle during the last few weeks, the insights they may have gained from tracking, and their interactions with parents and peers about their sleep and data.

The parents of all teens were also recruited for the field study. As shown in Table 2, we had 11 parents participated, with one of the parents being the mother of both teen 10 and teen 11 . We were very conscious of the power differences between teens and parents and the potential for tracking data to become a means of parental surveillance [8]. Hence, we always provided the teens with the choice as to whether they wanted their parent to be involved and if they wanted to be 
Table 2 Participant overview, showing age, gender, parents involved, and lifestyle factors tracked

\begin{tabular}{|c|c|c|c|c|c|}
\hline Teen & Age & Gender & $\begin{array}{l}\text { Mother }(\mathrm{M}) \\
\text { Father }(\mathrm{F})\end{array}$ & Tracking data & Sleep problem \\
\hline $\mathrm{T} 1$ & 17 & M & MT1 & $\begin{array}{l}\text { Assignments; phone use; stress; time with family after } 6 \text { pm; } \\
\text { video games; caffeine }\end{array}$ & - \\
\hline $\mathrm{T} 2$ & 17 & $\mathrm{~F}$ & MT2 & Alcohol; caffeine; exercise; phone; stress; family time; TV & - \\
\hline $\mathrm{T} 3$ & 14 & $\mathrm{~F}$ & MT3 & Assignments; exercise; phone; social media; stress; family time & - \\
\hline $\mathrm{T} 4 \mathrm{~S}^{*}$ & 13 & M & MT4S and FT4S & $\begin{array}{l}\text { Assignments; exercise; stress; time with family after } 6 \text { pm; TV; } \\
\text { video games }\end{array}$ & Takes melatonin to fall asleep \\
\hline T5 & 13 & M & MT5 & Assignments; exercise; TV; video games; stress & - \\
\hline T6 & 16 & $\mathrm{~F}$ & FT6 & Assignments; caffeine; exercise; part-time job; phone; stress & - \\
\hline $\mathrm{T} 7 \mathrm{~S}$ & 15 & M & MT7S & Exercise; social media; phone use; medication; assignments; stress & Sees sleep psychologist \\
\hline $\mathrm{T} 8$ & 16 & $\mathrm{~F}$ & FT8 & $\begin{array}{l}\text { Exercise; social media; phone; late night snacking; assignments; } \\
\text { stress }\end{array}$ & - \\
\hline T9S & 17 & M & MT9S & $\begin{array}{l}\text { Video games; exercise; TV; music; phone use; time with friends; } \\
\text { late night snacking; extra factor (pet in bed); stress }\end{array}$ & Sees sleep paediatrician \\
\hline $\begin{array}{l}\text { T10S } \\
\text { (sibling } \\
\text { of T11) }\end{array}$ & 15 & M & MT10S11 & $\begin{array}{l}\text { TV; video games; exercise; caffeine; stay up late on weekends; } \\
\text { late night snack; part-time job; texting; music; social media; } \\
\text { assignments; time with family after } 6 \text { pm; light in room }\end{array}$ & $\begin{array}{l}\text { Epilepsy requires medication } \\
\text { to sleep safely }\end{array}$ \\
\hline $\mathrm{T} 11$ & 13 & $\mathrm{~F}$ & MT10S11 & $\begin{array}{l}\text { Social media; exercise; video games; text messaging; assign- } \\
\text { ments; stress }\end{array}$ & - \\
\hline $\mathrm{T} 12$ & 17 & $\mathrm{~F}$ & MT12 & $\begin{array}{l}\text { Video games; exercise; part-time job; TV; assignments and } \\
\text { exams; stress; phone use }\end{array}$ & - \\
\hline
\end{tabular}

*Teens with diagnosed sleep problems are indicated with an S (e.g. T4S)

interviewed separately or with their parent. Most of the teens chose to interview with their parents, whilst two participants, $\mathrm{T} 2$ and T3, were interviewed separately in the first interview due to their parents both being nurses working night shifts. At the end of the study, we conducted an additional interview with parents and teens together to reflect on sleep, tracking, and related outcomes. Again, this was only done when teens agreed to invite parents to the interview and to share their SleepBeta data. With their permission, we revisited the visualizations in SleepBeta during the interview to interpret and reflect on the data with teens and parents.

We used a combination of inductive and deductive strategies for our thematic analysis [70]. Immediately after each interview, we listened to the interview recording and created mind-maps to summarise the main discussion points and to highlight possible codes and interesting quotes. We also transcribed each interview and the first and second author went through two rounds of coding all data using Saturate, an online tool for collaborative data analysis. This initial round of coding was primarily inductive, highlighting main themes raised by participants, such as their motivations to join the study, the perceived impact of physical activity, stress caused by exams, interactions with family members and peers, and insights into their sleep from SleepBeta. However, we also coded deductively: based on the stagebased model of personal informatics [11], we structured our codes around the steps of preparation, data collection, integration, and reflection. Since we struggled with the linear nature of the stage-based model where reflection is seen as an outcome, we turned to other theoretical perspectives on reflection to refine our themes. Our analysis was guided particularly by the levels of reflection [52] and the concept of reflection-in-action [53]. In the following section, we present four distinct but interrelated modes of reflection with sleep data: reflection in preparation, reflection, reflection upon revisiting data, and reflection through social interaction.

\section{Findings}

The findings highlight that revisiting personal data provided teens with opportunities to reflect on sleep and related habits, as per our initial aim. However, the findings also highlight that reflection is ongoing, with teens starting to reflect on sleep during the preparation for this study and throughout the data collection phase, both individually as well as through social interaction with parents and peers.

\subsection{Reflection in preparation}

Preparation and reflection often went hand in hand. For many teens, this study was the first time that they were invited to talk and think about their sleep habits. Particularly the card sorting activity was useful to help teens prepare for the study and to scaffold reflection, e.g. by surfacing concerns or questions in conversation with the research team. 
Teens started to inquire and make assertions about the influence between things they do in their daily lives and their sleep. For teens with pre-diagnosed sleep problems and their parents, this was an opportunity to reflect on their past and present efforts to improve their sleep habits.

\subsubsection{Acknowledge limitations of sleep knowledge}

As a starting point, reflection can mean being able to identify the limits of one's knowledge and a curiosity to learn more. For many (8/12) teens, this was the first time they examined their sleep. Hence, they were not aware of what their sleep patterns looked like, or what might constitute good sleep. These teens were not necessarily concerned about getting more sleep. Typically, teens were simply curious to see what the data might reveal about their sleep and its significance for their lives. For example, T8 was a 16-year-old student who had used a mobile app prior to our study to track her steps together with her sister, and she was curious about trying out sleep tracking to 'see how long I slept for, and how I was awake in the night, how well I slept that night-I've never really known'.

The SleepBeta cards were helpful to open up discussion with teenagers about the questions they had about sleep. For instance, $\mathrm{T} 8$ was often sleeping less than $7 \mathrm{~h}$ per night and questioned, 'Is that a good amount I'm sleeping?' Whilst some teens had an awareness of what a healthy sleep pattern looked like, others questioned what a healthy sleep pattern is. Often when teens were unsure about a lifestyle factor as shown on the SleepBeta cards, it was added to their daily questionnaire to enable a better understanding of the role each factor plays on sleep. For instance, T7S was unsure if the cleanliness of his bedroom impacted his sleep. Consequently, we encouraged T7S to address this question by adding cleanliness of bedroom to his SleepBeta diary. T11 stated, 'To my knowledge I don't have any sleep problems. I may have sleep problem I don't even know about', as a teen who was unsure about her sleep habits, preparing to further understand her sleep with SleepBeta.

\subsubsection{Control routines and sleep problems}

Four teens in this study had a diagnosed sleep problem: three teenagers required regular visits with a sleep psychologist or sleep paediatrician (T4S, T7S, and T9S) and one teenager (T10S) required medication for his epilepsy which interfered with his sleep. These teens and their parents were already knowledgeable about sleep because together they had tried many things to get the sleep problem under control. The parents saw this study as an opportunity to keep track of what they had been doing 'It's good to know this sort of thing, with this Fitbit he's keeping track.' (MT4S), and to try something new to gain control: 'He wants to find out what he can with the app. He has tried everything you know, people say 'I tried this this and this', and we've done all of that, so we want to try [SleepBeta].' (MT9S).

Based on the cards, teens and parents reflected on the medical advice they had received and what they had already tried to identify and control potential factors that may interfere with sleep. For example, T7S had been seeing a sleep psychologist and had made numerous lifestyle factor changes, which had been implemented as rules by his mother (MT7S). These changes included minimizing technology use in the afternoon, taking his ADHD medication (dexamphetamine) in the morning instead of at night to avoid feeling alert from the medication at night, and exercising frequently. His aim was to have a more regular routine: 'on a school day I wake up at 6AM, on a weekend I am allowed to sleep until 7AM' and MT7S expressed, 'it used to be a lot later but that's what the [sleep psychologist] said [to implement]' The sleep psychologist recommended sleeping only an extra hour on weekends to avoid sleeping in, and to stick to a regular sleep schedule.

Technologies used at night were the main concern for the parents of teens with diagnosed sleep problems. For example, T10S struggled with his sleep routine due to his epilepsy. He consumed his epilepsy medication (sodium valproate) to ensure a safe night's sleep. T10S's mother illustrated 'he goes to bed late and wakes up early, not by choice. He falls asleep every night reading [I know] because he breaks so many pairs of glasses. He probably goes to bed anywhere between 10:30 and 1AM'. T10S was motivated to find a more beneficial sleep routine. MT10S revealed the culprits, 'part of it's your epilepsy and the other part is because he's a teenage boy who is addicted to video games'.

\subsubsection{Inquire into relationships between sleep and studies}

The SleepBeta cards encouraged teens to reflect on the relationships between their sleep and their studies. Reflections on the cards with teens highlighted a tension and a desire to find a better balance between getting enough sleep and staying awake late at night to complete assignments or to prepare for exams. Teenagers knew that they should sleep at a reasonable hour to be energised to function optimally the next day. However, when presented with a choice to stay awake and study, or to sleep at a reasonable hour, teenagers in this study often chose to stay awake. A poignant example was T6, who was in her second-last year of high school and working hard to get outstanding grades to qualify for entrance into medicine school. One of the first things she said was that 'I'm so tired, I' $m$ so used to being tired. Last week I got like $12 \mathrm{~h}$ sleep total'. When prompted with the 'assignments and exams' card T6 stated 'That is affecting my sleep a lot, that is the reason I'm not getting sleep. I have 
to stay up and do my assignments, prepare for exams. That is most of the issues regarding sleep for me'.

Assignments and exams were also a cause of stress and anxiety. For example, T2 immediately chose the 'stress and anxiety' card. Like T6, she was in her second-last year of high school, which is a stressful time because the grades from the last 2 years of high school are the primary mechanism for ranking students for admission to tertiary education. T2 explained that 'I feel it really affects my sleeping patterns, stressing about studying for exams and assignments, I don't get much sleep, that's a big one'.

\subsubsection{Concerns and rules for technology access}

All teens selected cards that related to their technology habits at nighttime. They were aware that they used their phones, engaged on social media, played video games, or watched TV, and that excessive technology use could interfere with their sleep. However, they were typically not concerned about their own technology habits, nor did they intend any changes, unless it was a busy time for them at school. For example, T2 was aware of her social media use at night, and she had thought about changing these habits around assessment periods at school due to the impacts on sleep, 'texting and social media, [I want to] control it when it comes to exams. Prioritise so I don't have to worry about it so that you can get the proper sleep for it for the next day'.

Five parents used the cards to reflect on the rules they had in place to manage technology use at nighttime. All four teens with diagnosed sleep problems had rules to limit technology access in the evening and at night. However, also other parents reflected on rules. The rules typically varied for teens at different ages, and they also varied between school nights and weekends or holiday periods. For example, MT10S11 used an app to limit social media access on the phones of T10S and T11 (siblings). MT10S11 used the mobile apps 'OurPact on the adult's phone to block it [social media on the teen's phone], and OurPactJr on their [the teen's] phone so they see the times it will shut off'. On school nights, the locks were set at $9 \mathrm{pm}-7$ am for T11 (13 years old) and 9:30 pm-7am for T10S (15 years old). On weekends, the lock was set to 10:30 pm-8am for both siblings. These applications and rules were enforced because 'they were sneaking their phones after hours and then sleeping in' (MT10S11). SleepBeta offered an opportunity for parents to review such rules and check them with their child.

\subsection{Reflection in action}

The SleepBeta cards inspired several teens to make changes to their lifestyles and to reflect on their actions. Reminiscent of Schoen's reflection-in-action [53], these teens 'made a move', and reflections on their move fed into further action. Having to track actions through SleepBeta served as a reminder reflect in and on action. Even within the short period of 3 weeks, some teens found that trends and correlations in their data backed up their own observations and experiences, and thereby reaffirmed their actions. Whilst the initial interview often provided the starting point for actions taken by teens, reflection in action resulted from teens using SleepBeta independently without the researcher.

\subsubsection{Making a move on lifestyle changes}

Several teens were encouraged by the discussion in the first interview to 'make a move' in Schoen's sense [53], where they tweaked a lifestyle or technology habit to learn and reflect on the outcomes. Tweaks were typically short-lived. For example, T1 went without coffee, which had been on his mind for several months. However, T1 abandoned his move after 1 day because he felt more tired: 'on the first day I was really tired, I didn't have a coffee for once'.

Some tweaks lasted for several days or weeks, but the tweaks led to unintended consequences. For example, T3 experimented with using her phone less at night. In our first interview, she mentioned that she was interested in seeing if she could get more sleep to improve her performance at school and in sports (artistic roller skating, where she represented her country on an international level). Based on the cards discussed, T3 mentioned she may focus on 'probably texting before bed, umm, social media'. When we interviewed $\mathrm{T} 3$ again, she mentioned that whilst she was successful in limiting her phone use at night, in bed specifically, she ended up using her iPad to watch Netflix in bed. Whilst T3 made a tweak, it ended up by replacing one screen-based activity with another one.

\subsubsection{Discovery in action}

On occasions, teens made discoveries during the field trial through the routine of filling in the SleepBeta diary. For example, T3 stated that she was surprised to see how much she used her phone at night and how poorly she felt in the morning. Whilst T3's mother thought that T3 was 'the best sleeper in the family' (MT3), T3 stated that she 'felt like 2 or 3/10 in the morning, whereas before this study I thought I felt much better than this'. T3 also recognised that she was utilizing technology in her bed more than she originally thought she was because she had to track the numbers or hours spent on her phone each day. Keeping an online SleepBeta diary made T3 more aware of how much time she spent on the phone, how she felt in the morning, and the potential to improve her sleep habits. 


\subsubsection{Reaffirm ongoing lifestyle changes}

For some teens, reflection during tracking and revisiting the data provided reaffirmation to changes that they have made to their lifestyles. This was mostly visible in the context of exercise. Eleven of the 12 teens were interested in the influence of exercise on their sleep, and several of them (T1, T4S, T7S) experimented with walking or riding to school. These changes were prompted by the discussion of the cards or by coincidence. As illustrated in the example below, teens and parents found reaffirmation for their efforts by revisiting and reflecting on their Fitbit and SleepBeta data, which again fed back into their actions.

For T4S, this study coincided with ongoing attempts to be more active and outside. T4S was a 13-year-old teenager with a diagnosed sleep problem, whose doctor prescribed melatonin to help him fall asleep. During the first interview, he and his parents were curious to learn more about the relationship between exercise and his sleep, hoping that riding his bike more would allow $\mathrm{T} 4 \mathrm{~S}$ to unwind and fall asleep more easily. During the second interview, T4S and his parents explained how he got more active during the study period, how this was reinforced by the data - both the 10,000-step goal on Fitbit and the sleep data on SleepBeta - and how revisiting these data fed back into his actions. T4S illustrated, 'I think that was one of the things I found [through SleepBeta] that, if I was out most of the day [riding my bike] I would have a good night's sleep, and it kind of means, quite un-interrupted'. His mother elaborated how the goal setting may have encouraged further action: 'I think it was good for him, it motivated him to do a lot more. He had that sort of goal sitting there, fall short of your 10,000 steps today. So, you know I think it was good for him especially fitness wise because it's made him get out a little more in the fresh air. The more you burn your energy, the better you sleep, and the better sound sleep you get. Because you're really tired'.

\subsection{Reflection upon revisiting data and correlations}

The second interview provided an opportunity to revisit the data together with our participant and to reflect on their sleep. Teens could revisit their data at any time during the study, but most of the reflections described in this section stemmed from the final interview. The SleepBeta visualization aimed to highlight correlations between sleep and lifestyle and technology habits. Whilst such correlations were useful for some teens, we found that most teens were content by simply seeing that their sleep patterns were normal for a person of their age. Visualizations helped some teens to account for outliers in sleep data, and some teens used it to confirm their efforts to be physically active, yet for some teens, the visualizations also created more questions.

\subsubsection{Reassurance that sleep is normal}

A positive outcome for many teens was that the sleep data provided reassurance about sleep patterns, i.e. that the time asleep they were getting each night was within the 8 to $10 \mathrm{~h}$ recommended for children at their age [67]. This was particularly valuable for teens who did not have diagnosed sleep problems and for whom this was the first time they examined their sleep patterns. For instance, T3 initially was concerned that she did not feel refreshed in the morning, but taking part in this study and revisiting her sleep data throughout the study reassured T3 that her sleep was 'normal' in terms of sleep duration. T3 elaborated, 'When I started [to use SleepBeta] I didn't know how my sleep would be, when I saw my graphs on FitBit, I realised my sleep was good'.

SleepBeta also provided reassurance to some parents who had expressed concerns about technologies used in bed. To illustrate, the parent of $\mathrm{T} 2$ was initially concerned that her daughter may not get enough sleep due to technologies used in bed. During the first interview MT2 stated: 'I think she goes to bed way too late, she goes to sleep way too late, and she gets up early. ... She is using her phone in bed. She will say she goes to bed 8:30, 9 o'clock, but she'll be awake at 11' (MT2). However, her sleep data confirmed that T2 was obtaining more than $8 \mathrm{~h}$ of sleep on most nights, with an average of $8 \mathrm{~h}$ and $13 \mathrm{~min}$ per night. MT2 viewed the sleep data in the final interview and confirmed that the data proved to her that '[T2]'s sleep is great', a very different view from before she viewed the data.

\subsubsection{Account for outliers and surprises}

Teens often revisited the sleep data and interpreted it by accounting for surprises or outliers in the data, such as explaining how assignments and exams led to short and interrupted sleep or how weekends allowed them to sleep for longer. This was prompted by the interview, where we asked them to talk us through the data and provide us with their recollection of events that may have influenced their sleep data. At the same time, for some teens, the follow-up interview was the first time that they the revisited the data in depth and tried to make sense of it by recounting significant events and their actions.

In terms of outliers in the sleep data, several teens recounted their dilemmas of wanting to spend time studying versus wanting to get enough sleep before an exam. T1 recounted 'I was studying up until I think it was 9:30 pm/10 pm and then I decided I should sleep and be refreshed for the exam. However, it didn't quite end that way'. Instead, T1 stayed awake to study for his math exam and did not end up sleeping until 'around 12AM or 1AM ... that was the lowest [sleep duration] hour count' totaling at $4.5 \mathrm{~h}$ of sleep. Accounting also requires comparison 
of outliers with what might be considered normal, e.g. T1 compared his sleep patterns during exam time with school time outside the exam period: "during the school period I typically get 7-8 [hours of sleep], during the exams it drops to 6 '.

In terms of surprises, not all teens found reassurance in their data that their time asleep is within the recommended 8 to $10 \mathrm{~h}$ of sleep. Occasionally teens were presented with surprises about not getting enough sleep, which contradicted their expectations. T8, a 16-year-old teen without diagnosed sleep problems, was surprised when she revisited her sleep data during the interview, expressing 'my sleep is not very levelled-I thought I was getting seven hours of sleep [per night]'. As illustrated in Fig. 2, only 8 of the 22 days tracked in her study were within the recommended 8 to $10 \mathrm{~h}$. T8 was able to account for long and short nights of sleep, e.g. for the night where she only got $4 \mathrm{~h}$ of sleep, $\mathrm{T} 8 \mathrm{commented}$ 'That's a sleepover, that's definitely a sleepover'.

\subsubsection{Reconcile sleep trends and correlations with experience}

In revisiting data, teens were also referring to trends and correlations that emerged over time, and they sought to reconcile these with their own observations and experience. Trends and correlations were particularly meaningful for teens with diagnosed sleep problems, who went into this study with rules or assertions about lifestyle factors that may influence their sleep. Exercise was a concern for all four teens with diagnosed sleep problems. For example, T7S began riding his bike to school every day half way through the study, because her parent MT7S obtained an injury and was temporarily unable to drive T7S. Bike riding was not explicitly tracked by the SleepBeta diary nor the Fitbit device. However, T7S and MT7S both agreed that the trends in the sleep data, i.e. the improvement in sleep quality, were no coincidence, as the dates on the improvement in sleep quality on the graph aligned with MT7S's injury. Furthermore, SleepBeta indicated positive correlations between sleep efficiency and exercise intensity as well as exercise duration (Fig. 3).

SleepBeta was particularly designed to highlight correlations over time. In hindsight, this feature was less useful for the reflections of teens than expected. This may be partly because 3 weeks may not have been enough time for correlations to emerge. For example, T8 was surprised not to see correlations between her sleep and social media use during the field study. T8 explained that she reviewed the data independently but that 'social media didn't show up' and 'I don't know why'. $\mathrm{T} 8$ was aware that she utilised social media very often at night, to the point 'I'm looking at it [social media] until I pass out [fall asleep in bed at night]'. T1 on the other hand explained that the absence of correlations

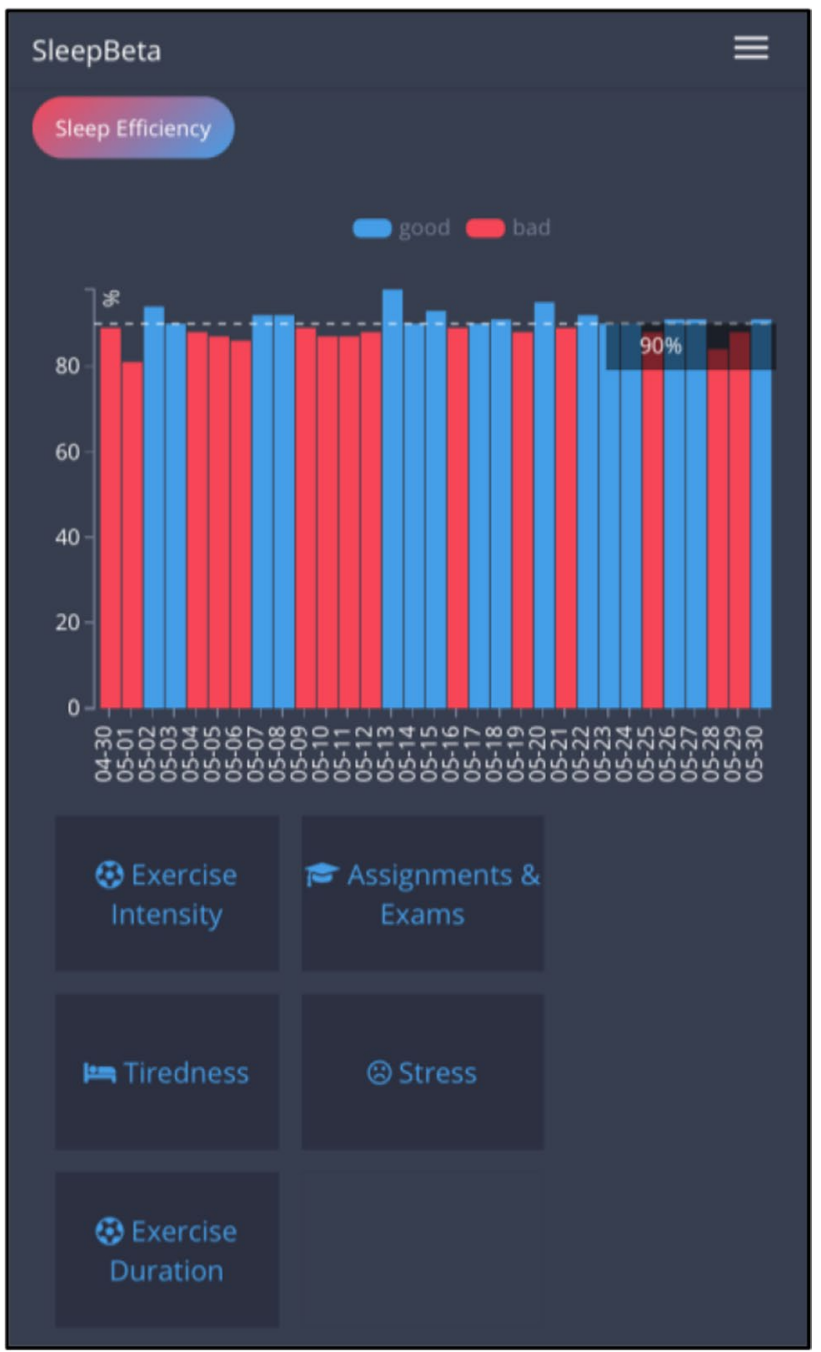

Fig. 3 T7's sleep efficiency data, showing more frequent positive sleep from May the 13th onward. Positive lifestyle factor correlations include exercise duration and intensity

between sleep and video games or social media was 'because I didn't spend quite as much as I usually do [on devices] because of the exam period'.

On the other hand, some correlations that were displayed appeared counterintuitive or ambiguous to teens. For example, SleepBeta showed a negative correlation between exercise and time asleep which was counterintuitive to $\mathrm{T} 7 \mathrm{~S}$, because it suggested that on days when he exercised more that his hours asleep were worse (less likely within the $8-10 \mathrm{~h}$ recommended). T7S dismissed this correlation, because he felt that being exhausted from exercise allowed him to sleep better. For T8, the correlations were more ambiguous. When we asked $\mathrm{T} 8$ to discuss the possible reasons for her variable sleep patterns, $\mathrm{T} 8$ initially pointed to the negative correlation between hours asleep and minutes sedentary displayed by SleepBeta (see Fig. 2). T8 explained: 
'I definitely think I' $m$ not active enough during the week at school yeah. The FitBit was always telling me to get up and walk around. I sit at school and then I get home then I just fall into bed and watch TV'. During the end of the interview, T8 and her parents reflected on her physical activity, which made us question the correlation displayed on SleepBeta. We learnt from $\mathrm{T} 8$ and her parents as well as the Fitbit physical activity data that $\mathrm{T} 8$ was regularly walking and meeting her 10,000 step goals and on top of that playing sports on Thursdays and Saturdays. Hence, whilst T8's initial concerns about sedentariness may have been plausible, they may have also been ill-founded. Unfortunately, the SleepBeta design explored in this study provided no way for us to examine the correlation further during the interview (e.g. through an illustration of sleep and sedentariness that shows the relationship for each day on a scatter plot). Hence, we finished the study without resolving the relationship between exercise and sleep for $\mathrm{T} 8$.

\subsection{Reflection through social interaction}

Reflection often occurred through dialogue with others. Until now we have described how such reflection occurred through our own interactions with teenage participants during the study interviews. Beyond that, the teens in this study described interactions and reflections on sleep with family members, peers, and coaches.

A major concern in setting up this study was how to encourage reflection in interaction with others, without undermining the privacy and agency of teenage participants. As described next, we opted for an approach where teens can manage the boundaries about the data they collect and share for reflection in a way that suits their family dynamics.

\subsubsection{Parent-teen teaming for reflection}

Parents and teens worked closely together either when teen had a diagnosed sleep problem, or when both parents and teens were self-tracking and thereby sharing and reflecting was reciprocal.

In the four families with teens with diagnosed sleep problems, we found that parents and children were already a team with a shared mission to establish sleep habits. Here, parents and teens discussed not only their sleep data, but also lifestyle data that was automatically collected by FitBit as well as the manually inputted data from the SleepBeta diary. These parents were often interested in the sleep data, and utilised the lifestyle data to understand what was aiding sleep. Parents of teens with diagnosed sleep problems encouraged healthy change in lifestyle (MT4S, MT7S), often by encouraging their teens to complete their daily exercise and meet their goals (e.g. MT4S encouraged T4S to reach his daily step count goal to aid his sleep).
Teaming up in these family contexts did not mean that parents and children evenly shared responsibilities. SleepBeta provided teens with diagnosed sleep problems with an opportunity to take on more responsibility by collecting their own data and monitoring their outcomes. However, decisions about bedtimes and technology access were ultimately made by parents. For example, MT9S had tried numerous sets of rules for T9S to improve his sleep routine. 'I went 18 months without anything [technology in my room] and it makes it worse, I was looking for something to do', T9S illustrated as MT9S agreed to remove his Xbox and TV from his bedroom in hopes of improving his sleep pattern. MT9S relaxed these rules and allowed technology back into the bedroom when she recognised that T9S was still not sleeping, 'he'd walk the floors with his hands up the walls' she illustrated.

We also found four family teams where parents were also self-tracking, which meant that both teens and parents could share and interpret each other's data. The parents of T7S, T10S, T11, and T12 were tracking their fitness and shared step counts with their children. For example, MT7S sets an example in her household by being active and ensuring her children are active and involved in sport programmes such as Ninja Warrior Training (obstacle courses). Sometimes MT7S would compare her step count to T7's step count to find that she had done less than him. MT10S11 and MT12 tracked their calorie intake and step count with a mobile phone application (MyFitnessPal). MT10S11 shared calorie information and step counts with her children T10S and T11, and strived to cook healthy meals for her family with the assistance of MyFitnessPal and its food information database. Health data was primarily shared through household conversations initiated by both the parent and the teen. T12 and MT12 revealed that they were 'friends' on the MyFitnessPal app, enabling each other to view one another's weight loss progress through the application itself, subsequently leading to household conversation.

\subsubsection{Boundary management in reflection with parents}

We sought to put teens in control about setting boundaries for the involvement of their parents. All parents were invited to this study for offer their views on their child's lifestyle and sleep habits, and to support their child with self-tracking if needed. When it came to sharing data, however, the teens were in control. They could decide if they wanted to share data during interviews with parents, as well as if they wanted to share and reflect on any data in between interviews.

Overall, teens were open to the idea of sharing and reflecting on data with their parents, but very little sharing happened in families with teens with healthy sleep. Some teenagers shared data when they were challenged in a playful way by their parents. For example, T8 achieved 
her 10,000-step goal 'pretty much every day'. However, when her father said that he did not believe her, she could refer to her personal data to prove how active she was. However, we are not aware of any similar challenges regarding sleep outcomes.

Parents of teens with healthy sleep had no access to their child's sleep data. The parent's role was typically limited to reminding their teenage child to keep tracking through the SleepBeta diary. For example, MT2 reported questioning T2 often: 'Have you got the FitBit on?'; 'Have you filled in your diary?'.

Unlike other teens with diagnosed sleep problems, T10S did not share his SleepBeta data with his parents either. From our conversations, we observed that T10S was generally maintaining strong boundaries with parents and kept his personal concerns to himself. His data showed that he had only slept for the recommended $8-10 \mathrm{~h}$ once during the study period. His late bedtime and long sleep-ins were already a source of tension during the first interview, with MT10S teasingly yet firmly suggesting that 'That's a lie-you sleep in until 1:00 PM'. The family also had strict rules to restrict social media at night, though T10S still had unrestricted access to video games (also because MT10S plays video games at night herself), which is why T10S kept the SleepBeta data to himself.

The interview with T7S provided an example of how teens maintain boundaries with their parents by not tracking potentially relevant data. Like other teens, T7S was aware that whilst he was not concerned about technologies used at night that his parents may be concerned. When we asked T7S to open his laptop to set up SleepBeta, we inadvertently created a tense situation that may have raised his parent's concerns. MT7S noted a video game was still running in a browser window and she pointed at the laptop and asked with a concerned expression: 'is that a game? [n]' T7S sought to repair the situation by stating: 'no!' and he quickly closed the browser window with the game. In hindsight, we also note that $\mathrm{T} 7 \mathrm{~S}$ had not chosen a card to discuss his digital game play, which could have been an attempt to avoid potential scrutiny in the shared interview with his mother.

Whilst the interview inadvertently created a moment of tension when the game was visible on the laptop, we take some consolation that our study design provided teens with the freedom to choose factors that they wished to track. This in turn also meant that teens could choose what they may wish to hide from their parents to preserve their privacy when sharing and discussing their SleepBeta data. We acknowledge that we did not have an opportunity check our interpretation in private with the teen and that our knowledge on his actual game play is limited.

\subsubsection{Reflections with peers and coaches}

Several teens reported discussing and reflecting upon sleep with peers and mentors. For most teens, sleep was not a topic that they would normally discuss with their peers. However, the SleepBeta study provided a prompt to introduce this topic into discussions with peers. For example, T3 explained the SleepBeta study to her friends at school when she was asked why she was wearing a FitBit device. $\mathrm{T} 1$ shared and revisited data with peers at school. He stated that he discussed 'things like quality of sleep, efficiency and that sort of thing and how that maybe helped certain days' with 'a close group of friends'. Through these discussions, he identified that sleep is in fact a concern for peers, stating that for 'most of our school, sleeping is very frequently low'.

Some participants in our study were known to each other and collaborated in interpreting each other's data. T10S and T11 were siblings, who reminded each other to keep track through their diary and to compare their exercise and sleep data. T4S and T5 joined the study together as friends and neighbours. During T5's interview, T4S was present and ended up aiding T5 in understanding some questions and sensemaking of his data. When we asked T5 to tell us what he had find in the data, T5 responded, 'what do you mean?' T4S stepped in to scaffold reflection: 'any patterns, did you see any times, things you'd do that affect how much sleep you got?'.

Some teens also sought to involve peers and coaches to revisit and reflect on their sleep and exercise data. T2 and T3 were both athletes (artistic roller skaters) who represented their country on an international level. These teens trained 5 days a week, with numerous exercises outside of training to build and maintain strength. Hence, T2 and T3 were curious to see if SleepBeta could provide them with insights into how they might sleep and perform better. $\mathrm{T} 2$ stated 'exercising often-I feel like it makes me sleep easier, it makes me more tired. Umm, yeah, I don't know' (T2). T3 explained that they sought to 'compare steps and try to figure out if the FitBit step tracker counts [while] skating, even though the coach said it wouldn't work'. In the end, T2 and T3 found that the FitBit did not accurately represent their exercise, because it would only count steps based on their arm movements. Despite the inaccurate data, T2 and T3 kept comparing their exercise data, with T3 stating 'I have more arm movements in my routines than $\mathrm{T} 2$ '.

\section{Discussion}

This field study offers novel insights into how teens reflect on their sleep, technology, and lifestyle habits. Being a teenager involves moving from a more dependent child to being a more independent adult [71]. In our study, we investigated 
how this transition in independence affects reflections in sleep-tracking. Unlike prior studies with teens, which were driven by sleep health experts [1] or by families as a whole [10], our study was led by the concerns and questions of teens themselves. Hence, teens were not only collecting data, but they were also invited to ask questions, to engage with their own data, to share insights, and to reflect upon the inquiry process.

Teen-led reflections in turn highlighted concerns and questions that were different from prior work on sleep and personal informatics. First, prior work emphasised concerns about the impact of social media and video games used before bedtime $[1,6,15]$ as well as how individual behaviours affect the rest of the family [10]. In our study, technologies and impacts on other family members were typically only of concern to teens with pre-diagnosed sleep problems and their parents. The main concerns for generally healthy teens, on the other hand, were often rather simple: whether they got enough sleep, how to best balance sleep and studies, and how physical activity might influence their sleep. Second, the motivations of teens with pre-diagnosed sleep problems and their families were similar to those of adults reported in related work [23, 24]: to better understand their sleep problem and to pursue improvements through lifestyle modifications. The inquiries of generally healthy teens, on the other hand, were typically open-ended and spurred by general curiosity. Third, like adults [26, 32], teens with prediagnosed sleep problems and their families considered a wider range of metrics to infer the quality of their sleep, including time awake at night, wakeup freshness, and sleep efficiency. Generally healthy teens, on the other hand, used their time asleep as an indicator of sleep quality. Finally, unlike prior personal informatics work with adults [49], none of the teens in our study appeared to ruminate on their sleep data. Teens whose data showed that they did not get enough sleep justified it with reasons like studying, rather than feeling concerned about the short hours.

For personal informatics researchers, our findings highlight that reflection is not a distinct stage but an ongoing process throughout all stages of the self-tracking process. This is hardly surprising - after all, the main aim of personal informatics is to obtain self-knowledge [11]. We are also aware that the intertwined nature of reflection with preparation [72], data integration [42], data collection, and action $[12,73]$ has been reported before. However, in light of such ongoing reflection, our findings offer sensitizing concepts to study and design for different types of reflection. 'Reflection upon revisiting data' offers a more accurate description than simply 'reflection' for the late stages of the stage-based model [11] and the lived informatics model of personal informatics [12] where individuals review numbers and visualizations to take action. 'Reflection in action', as characterised by Schoen [53], highlights the intertwined nature of reflection and action. Often it was only by taking an action (e.g. drinking less coffee) that teens were able to reflect on their sleep habits, as well as on the impact of sleep their experience in school, sports, and in interactions with others. 'Reflection in preparation' highlights that reflection can start early, even before a person has collected data. Finally, 'reflection through social interaction' highlights the importance of dialogue with peers, parents, coaches, and researchers to gain new insights.

In the following sections, we discuss two of these concepts in more detail. First, we discuss the significance of reflection in preparation for self-tracking and the need for scaffolding. We discuss the significance of card sorting for scaffolding and highlight design opportunities. Next, we discuss the importance of reflection through social interaction for teens. Based on Altman's theory of privacy regulation [74], we discuss how interactions about self-tracking posed a privacy challenge for teens, but also how teens negotiated the boundaries of their interactions and reflections to protect their privacy. Finally, we reflect on the limitations of this study and opportunities to improve the SleepBeta design.

\subsection{Scaffolding reflection in preparation through card sorting}

A key finding was that reflection in personal informatics is starting early, even prior to data collection, rather than something that happens at the end when a person has collected enough data [11]. Our finding aligns with Baumer [38], who pointed out that reflection is often an ongoing process of intentional and conscious inquiry. Other studies of personal informatics systems have made similar observations, stating that reflection is tightly coupled with earlier stages of data collection, integration, and action $[42,73]$. In some studies, participants were invited reflect during the preparation stage to set up the personal informatics system, i.e. to establish exercise goals [72] or the health symptoms and triggers they wished track [75]. In our study, reflection in preparation also aided teens in deciding what lifestyle and technology factors to track based on established evidence in sleep science research. Unlike in prior studies, however, reflection in preparation was not limited to potential data collection and action, but it more broadly addressed the role of sleep in the broader context of their families, rules around technology access, and experiences at school, in sports, and in other everyday life contexts.

The key difference between 'reflection in preparation' and other forms of reflection in the context of personal informatics is that it is based on personal and lived experience rather than on data. Teens asked themselves how well they slept, how sleep mattered for their lives, and efforts they had made in the past to better understand and improve their sleep. Reflection during the preparation stage was important 
for teens, because they were largely new to self-tracking and many participants had not experienced sleep issues before. We contend that our insights also present an opportunity to better support reflection in preparation for adults who contemplate sleep-tracking, since many adults find it difficult to make sense of sleep data and the various factors that can affect their sleep [26-28]. Beyond that, insights from reflection in preparation are important, because barriers in earlier stages affect the later stages [11] and increase the likelihood of lapsing self-tracking [12]. Conversely, interesting questions and directions emerging from the preparation stage can positively affect data collection, insights from the data, and actions taken.

A key contribution of this study is the SleepBeta card set, which was important to scaffold reflection in the absence of personal data. Looking back, we had not intended SleepBeta cards to be a contribution. We simply introduced cards into the study as a way to start a conversation about sleep tracking, similar to how qualitative researchers use cards and other props to elicit information from participants about their lived experience [76] and their mental models [77]. However, as highlighted in the findings, the SleepBeta cards were a crucial scaffold that allowed for immediate reflection without the need for having data collected. By reviewing and selecting cards, teens started to think what they already knew about sleep - based on both general knowledge and self-knowledge - and what they wanted to find out. Furthermore, we found that the SleepBeta cards were also effective to bring new knowledge into the reflective dialogue. Designers often use cards to bring new perspectives to their reflective conversations in the context of a design process, e.g. through cards that present new methods [78], technology concepts [79], human values [80], and theoretical concepts $[81,82]$. Based on a review of the sleep health literature $[1,6,15,17,55-58]$, the SleepBeta cards provided new perspectives on sleep to the conversations with teens to reflect on their circumstances. The back of the cards offered explanations about the impact of a particular lifestyle or technology factor, together with questions about their circumstances and behaviours, which teens read and discussed with us. Through this dialogue, teens started to make assertions on how their use of technologies, studies, exercise etc. may influence sleep, and they also started to work out what data they wanted to track. We hope that the SleepBeta cards (provided in the Appendix) will also be useful for other researchers, health professionals, and individuals interested in conversations about sleep and personal data.

We see several opportunities to further enhance the value of SleepBeta cards to scaffold reflection in preparation. Firstly, health coaching $[83,84]$ highlights opportunities to deepen reflection with cards through additional content. Typically, health coaching starts with helping individuals to identify their own values and visions of health by asking teens which areas are important for them, where they perceive challenges, or require support [83]. In our study, we saw that teens wanted to improve an existing health condition, improve performance at school or in a sport, or learn how to stay well, which in turn framed their choice cards and their self-tracking enquiries. Adding such values and visions to the card set can deepen reflection on values, before teens select cards on particular lifestyle and technology factors. Values in health coaching also go hand in hand with goal-setting [83, 84]. Additional questions on the cards into teens' long-term goal can strengthen the reflection and help teens understand how their goals support the bigger picture of their lives [83]. Knowing values and goals, in turn, allows for additional scaffolding based on personal data. Based on coaching literature and workshops, Kocielnik et al. [85] devised reflective questions for physical activity data. Their questions were structured around noticing personal patterns, understanding the personal situation from different perspectives, and developing insights for future actions, which would also strengthen reflection on sleep.

We also see opportunities for different kinds of dialogue for reflection in preparation. In our study, SleepBeta cards relied on a researcher to scaffold reflection in dialogue with teens. One way to scale up such interactions is through workshops. Whilst workshops are often used to share and reflect on personal data collected $[9,86,87]$, we contend that the SleepBeta cards can also work well in workshops where teens pair up with fellow teens to reflect on their sleep and decide what data they wish to explore. Alternatively, cards also hold potential to scaffold conversations around sleep in families, without a researcher present. Pina et al. [10] highlight the importance of revealing family health as a value and the desire of parents and children to better understand how the sleep and other behaviours of a family member affect others. SleepBeta cards provide an opportunity for such reflective conversations within families, but without the need for surveillance through personal data.

Whilst the human-to-human dialogue based on SleepBeta cards was a key strength of this study, we also highlight design opportunities to scaffold a similar dialogue through technology. The work of Kocielnik et al. [85, 88] highlights how conversational agents can provide users with questions to prompt reflection, which mimic the interactions with a human facilitator. Inspired by this work, we see clear benefits for a conversational agent to connect with the SleepBeta cards and the dashboard. A possible scenario is for users to interact with a conversational agent by choosing SleepBeta cards with NFC tags embedded, which could be used to trigger questions by a conversational agent within SleepBeta about values, goals, and technology and lifestyle factors relevant to their personal circumstances and the cards chosen. On the one hand, this would retain the physical qualities of card sorting and allow teens to lay out cards on a table and 
sort them as they reflect on their personal circumstances. On the other hand, scanning the card on the phone can be used to trigger reflective questions through a conversational agent to prepare for self-tracking. Similar to the work of Lee et al. [72], responses to such questions can be used to set up the SleepBeta diary with the data they wish to collect and to personalise and the accompanying dashboard. Beyond that, as in the work of Kocielnik et al. [85, 88], engagement with a conversational agent can promote reflection around observations and trends in the data. The integration of card sorting and personal informatics applications has the potential to empower not only teens, but to extend the reach and the value of personal informatics tools to a broader group of people interested in sleep and wellbeing.

\subsection{Managing privacy in reflection through social interaction}

A second key finding was that 'reflection through social interaction' was important to gain insight in dialogue with others. Beyond the dialogue with the research team, teens reflected on sleep with their existing network of relations: their family members, peers, and coaches. As highlighted by Suchman [89], new technologies rely on such networks of relations to become integrated with familiar environments and practices. In our study, parents often had to remind teens to keep tracking. More importantly, some parents and teens worked closely together as a team to interpret and reflect on personal data. This was particularly the case if parents were tracking their own lifestyles and teamed up with their children, or when the teen had a diagnosed sleep problem. In the latter case, the entire family was keen to improve their sleep habits, and thereby tried to support regular tracking and to interpret and contextualise data. These observations also align with the argument made by Pina [10] that health in families is a shared concern, especially when a child has a chronic health concern, and that it may be more fruitful to think about family informatics instead of personal informatics.

We acknowledge that whilst important, reflection through social interaction in and of itself is hardly novel. It is well known that social interaction is essential to teens to form and maintain personal relationships and to develop a sense of identity and purpose [90]. Likewise, reflective processes are often characterised as a dialogue [52]. Even in the context of personal informatics, reflection has been shown to be highly social, either through family networks [10], online social networks [73], school environments [9, 86], data sharing workshops [87], and presentations of insights and personal experiences with peers [24, 42].

However, our study highlights two novel aspects of reflection through social interaction. Firstly, a key difference in our study was that we focused on teens directly, rather than their families [73] or school classes $[9,86]$ as whole. This is important, because adolescence as a life stage is characterised by a transition from being a dependent child towards being an independent adult [91]. Hence, in treating teens as principally independent in self-tracking, our findings highlight key questions that teens reflected upon, such as what constitutes normal sleep, its relationship to studies and exercise, and what lifestyle facets they may tweak to improve their sleep. At the same time, our findings also point to the different contributions to reflection that different relations made: with peers, sleep and exercise data offered a ticket to talk about wellbeing and a way to normalise that sleep is a concern during exam time. Coaches were asked to revisit and reflect upon the relationship between sleep and exercise. Parents assisted teens to co-construct insights into a range of issues from technology use at night, to the impact of exercise, to exploring reasons for sleep disruptions.

Secondly, the findings showed how teens negotiated the boundaries of their interactions and reflections to protect their privacy. Our analysis was inspired by Altman's theory of privacy regulation [74]. Altman's key idea is that privacy is managed dynamically through an ongoing process where individuals open up or close themselves off from others. This process is dynamic and dialectic, meaning that people regulate their boundaries depending on their own expectations as well as the expectations of others in a particular context. Boundary regulation is particularly important for teens, as they negotiate increasing levels of independence with their parents around their sleep times, studies, work, technology use, etc. [91].

We found that self-tracking technologies pose a challenge for teens as they can disrupt boundary regulation. This was most obvious in the case of T7S, who was trying to hide a video game running on the computer which advertently revealed his game play to his parent. Following Altman [74], Palen and Dourish [92] highlight how information technologies can disrupt the regulation of boundaries over time, because they capture information that may otherwise be ephemeral [92]. Self-tracking technologies are designed to highlight incidents and trends over time, which can stand in conflict with how teens want to present themselves to their parents. Even though we found that sleep and lifestyle data appeared to be largely free from tension (and sometimes were even celebrated as achievements), we saw that technology use at night constituted a point of contention and ongoing negotiation. Technologies were particularly a concern for parents, who often strictly regulated their use and sometimes even monitored technology screen time.

Our findings also illustrated how teens negotiated privacy boundaries with self-tracking technologies to avoid tension. Firstly, teens were in control over what they selected to track in the first place. Whilst all teens tracked their sleep, they were able to avoid potentially contentious data, e.g. as in 
T7S's case, who decided not to track how much time he spent playing computer games even though it was a concern of the parent. Secondly, teens were able to self-report on how much time they spend using technologies at night. Whilst there are many systems that automatically keep track of screen time, which were also used by some of the parents in this study, we opted for a manual approach that gives agency to teens. Finally, teens were in control over whether they wanted to include their parents in the final interview and what information from SleepBeta they wanted to disclose. Hence, whilst adolescence is sometimes seen as time of storm and stress [91] and particularly screen time is often a source of tension between parents and teenage children [5, 21], we did not find this to be the case in our study. Instead, sleep and lifestyle tracking became integrated with the ongoing negotiation of boundaries and rules between teens and parents.

\subsection{Reflection on study limitations}

Looking back at our study aims, we had expected to see more reflection upon revisiting data, particularly from the correlations, as this was one of the main features of SleepBeta. We are aware that relying on information visualised on dashboards is not sufficient for reflection to occur [48]. Furthermore, as presented in the findings, correlations presented on SleepBeta were often as expected (e.g. correlations between sleep and exercise, assignments, and stress), or they were counterintuitive and hence dismissed. Participants may have benefitted from seeing more correlations on their SleepBeta profile. Teens who attended school throughout the study period may simply not have had enough variability in their data, or statistically speaking, a restricted range. In this regard, a longer study period and encouraging teens to experiment more with their lifestyles may have led to more variation in the data, which in turn may have led to more significant correlations showing up on SleepBeta. Related work also highlights opportunities to present correlations more effectively for reflection. One example is to show the strength of correlations [32], so that teens can determine the plausibility of the data when they compare it with their subjective experience. Another example is to let users access sleep data and lifestyle data side by side in a timeline [31, 93], so that they can better understand and examine interrelationships based on perceivable trends in time series data. Another pitfall with univariate correlation analysis is the potential effect of confounding factors, which may have led to counterintuitive correlations shown on the dashboard. An alternative method is to apply multivariate regression analysis or principal component analysis, which allows to identify factors that best explain the variations in the target sleep metrics.
We had also expected that teens would revisit and reflect more independently on the SleepBeta data, outside the study interviews. We asked parents to support and encourage their children to engage with SleepBeta, but due to privacy concerns, their role was often to remind teens of collecting data rather than revisiting it. In hindsight, we could have adjusted our methods to encourage teens in the initial interviews more explicitly to revisit the data each week, or through text messages prompts and questions during the 3-week period, or through a simple diary to note reflections and insights during the study. From a technology design perspective, notifications when new correlations emerge or question prompts as in the study of Kocielnik et al. [85] could have been helpful teens to revisit their data more often. On the other hand, however, we had the advantage of being present and witnessing when teens reviewed and reflected on their data on SleepBeta, which offered us detailed insights into their open questions and their interpretations, especially when they had to reconcile data that appeared to contradict their subjective experience.

We acknowledge that our findings come from a small and diverse cohort. As with any qualitative study, a larger cohort and longer study period would strengthen the credibility of the contributions. However, the 12 teens in our study and their family members provide a solid foundation for our contributions, because we reached a point of saturation early on in the study on the four types of reflection, and also because the findings are based on an established framework [11]. A meta-review by Caine [94] shows that 12 participants is the most common sample size in human-computer interaction research, which provides further support for the credibility of this work. Nevertheless, additional participants may have given us additional details, i.e. on the theme of reflection upon revisiting data.

We also acknowledge that the sleep data collected did not meet the expectations of medical study. The sleep data came from a Fitbit Charge HR device, which is not a medical grade device, nor has the Fitbit data been verified through selfreported data on how long and how well participants slept. Participants were asked to track their wake-up freshness as a subjective measure to compare with their Fitbit data on sleep length, but we relied on Fitbit data to record the total sleep time and time awake at night. Whilst not classified as a medical-grade sleep tracker, Fitbit Charge HR devices are generally more accurate than self-reports [95], especially for people with sleep disorders [96, 97]. Furthermore, validation studies with adolescents show that Fitbit Charge HR devices provide good agreement with gold-standard PSG data on total sleep time and sleep efficiency [65, 66].

A final question is whether SleepBeta as an intervention promoted reflective thinking on sleep and personal wellbeing more broadly. The findings clearly show new insights that teens gained from their various reflections, from knowing 
how much sleep they needed to sleep, to the impacts of exercise, studies, and technologies used. However, in hindsight, it would have been interesting to understand better if it also changed their perspective on sleep and wellbeing (showing evidence of double-loop learning [35]), and whether SleepBeta advanced their reflective thinking abilities as a whole. To this end, we could have asked teens to fill in a questionnaire for reflective thinking [36] at the start and at the end of the study to unpack the impact of SleepBeta on their reflective thinking.

\section{Conclusion}

In this study, we have invited teens to reflect on their sleep and related lifestyle and technology habits. This has been inspired by prior studies where teens have been subjects in research, but with little agency to explore and reflect on their own sleep data. Hence, we invited teens follow a selftracking approach where they tracked their sleep. To this end, we designed SleepBeta, which consisted of a set of cards with factors known to influence sleep, a diary app to track relevant factors, a fitness tracker, and a dashboard to visualise data and correlations between sleep and diary data.

The first takeaway from our study is a better understanding of reflection and its importance in the design and study of personal informatics systems. From our study, we learnt that reflection upon revisiting data is not the only nor the predominant mode of reflection. Reflection is an ongoing process that starts before data is collected. In reflection in preparation, teens discussed their subjective sleep experience and their questions and concerns about factors that may influence their sleep, like their studies and technologies used at night. Critical to this kind of reflection was a set of cards about lifestyle and technology habits that can affect a teen's sleep. We conclude that card sorting is a powerful means for reflection because cards can make health knowledge accessible to teens (and others interested in sleep-tracking), prompt questions about personal values and goals, and provide a path forward to for data collection and action.

The second takeaway from our study is the significance (and difficulty) of reflective dialogue with peers, family members, and researchers. Despite its name, self-tracking is not an individual endeavour. Instead, it relies on the support of existing networks of relations to reflect on data and experiences. However, interactions around personal data also introduce challenges to the privacy of teens. Based on our technology design and our observations around boundary regulation, we conclude that personal informatics systems need to be designed to give teens ultimate control. Teens need to control not only what data they might share and discuss with others, but also what data they collect, and more fundamentally, if they wish to track any information at all.
Supplementary Information The online version contains supplementary material available at https://doi.org/10.1007/s00779-021-01661-x.

Acknowledgements We would like to thank all participants for their support in this study. We are thankful to Cameron Happer, Sean Nolan, Thomas Cunningham, and Tae Lim Son who helped to develop and pilot the SleepBeta app. We also thank Dhaval Vyas for his support in developing the SleepBeta cards and in recruiting participants.

Funding Open Access funding enabled and organized by CAUL and its Member Institutions.

\section{Declarations}

Conflict of interest The authors declare no competing interests.

Open Access This article is licensed under a Creative Commons Attribution 4.0 International License, which permits use, sharing, adaptation, distribution and reproduction in any medium or format, as long as you give appropriate credit to the original author(s) and the source, provide a link to the Creative Commons licence, and indicate if changes were made. The images or other third party material in this article are included in the article's Creative Commons licence, unless indicated otherwise in a credit line to the material. If material is not included in the article's Creative Commons licence and your intended use is not permitted by statutory regulation or exceeds the permitted use, you will need to obtain permission directly from the copyright holder. To view a copy of this licence, visit http://creativecommons.org/licenses/by/4.0/.

\section{References}

1. Harbard E, Allen NB, Trinder J, Bei B (2016) What's keeping teenagers up? Prebedtime behaviors and actigraphy-assessed sleep over school and vacation. J Adolesc Health 58(4):426-432. https:// doi.org/10.1016/j.jadohealth.2015.12.011

2. Carskadon MA (2011) Sleep in adolescents: the perfect storm. Pediatr Clin North Am 58(3):637-647. https://doi.org/10.1016/j. pcl.2011.03.003

3. Cain N, Gradisar M (2010) Electronic media use and sleep in school-aged children and adolescents: a review. Sleep Med 11(8):735-742. https://doi.org/10.1016/j.sleep.2010.02.006

4. Lemola S, Perkinson-Gloor N, Brand S, Dewald-Kaufmann JF, Grob A (2014) Adolescents' electronic media use at night, sleep disturbance, and depressive symptoms in the smartphone age. J Youth Adolesc 44(2):405-418. https://doi.org/10.1007/ s10964-014-0176-x

5. Davis K, Dinhopl A, Hiniker A (2019) "Everything's the phone": understanding the phone's supercharged role in parent-teen relationships. In: Proceedings of the 2019 CHI Conference on Human Factors in Computing Systems. ACM, New York, pp 1-14. https:// doi.org/10.1145/3290605.3300457

6. Exelmans L, Van den Bulck J (2017) Binge viewing, sleep, and the role of pre-sleep arousal. J Clin Sleep Med 13(8):1001-1008. https://doi.org/10.5664/jcsm.6704

7. Neff G, Nafus D (2016) Self-tracking. MIT Press, Cambridge

8. Jørgensen MS, Nissen FK, Paay J, Kjeldskov J, Skov MB (2016) Monitoring children's physical activity and sleep: a study of surveillance and information disclosure. In: Proceedings of the 28th Australian Conference on Computer-Human Interaction (OZCHI 2016). ACM, New York, pp 50-58. https://doi.org/10.1145/3010915.3010936

9. Potapov K, Lee VR, Vasalou A, Marshall P (2019) Youth concerns and responses to self-tracking tools and personal informatics 
systems. In: Extended Abstracts of the 2019 CHI Conference on Human Factors in Computing Systems. ACM, New York, pp 1-6. https://doi.org/10.1145/3290607.3312886

10. Pina LR, Sien S-W, Ward T, Yip JC, Munson SA, Fogarty J, Kientz JA (2017) From personal informatics to family informatics: understanding family practices around health monitoring. In: Proceedings of the 2017 ACM Conference on Computer Supported Cooperative Work and Social Computing. ACM, New York, pp 2300-2315. https://doi.org/10.1145/2998181.2998362

11. Li I, Dey A, Forlizzi J (2010) A stage-based model of personal informatics systems. In: Proceedings of the SIGCHI Conference on Human Factors in Computing Systems (CHI 2010). ACM, pp 557-566. https://doi.org/10.1145/1753326.1753409

12. Epstein DA, Ping A, Fogarty J, Munson SA (2015) A lived informatics model of personal informatics. In: Proceedings of the 2015 ACM International Joint Conference on Pervasive and Ubiquitous Computing. ACM, New York, pp 731-742. https://doi.org/ $10.1145 / 2750858.2804250$

13. Tarokh L, Saletin JM, Carskadon MA (2016) Sleep in adolescence: physiology, cognition and mental health. Neurosci Biobehav Rev 70:182-188. https://doi.org/10.1016/j.neubiorev.2016.08. 008

14. Lo JC, Lee SM, Lee XK, Sasmita K, Chee NIYN, Tandi J, Cher WS, Gooley JJ, Chee MWL (2018) Sustained benefits of delaying school start time on adolescent sleep and well-being. Sleep 41(6):zsy052. https://doi.org/10.1093/sleep/zsy052

15. Levenson JC, Shensa A, Sidani JE, Colditz JB, Primack BA (2016) The association between social media use and sleep disturbance among young adults. Prev Med 85:36-41. https://doi. org/10.1016/j.ypmed.2016.01.001

16. Hale L, Kirschen GW, LeBourgeois MK, Gradisar M, Garrison MM, Montgomery-Downs H, Kirschen H, McHale SM, Chang A-M, Buxton OM (2018) Youth screen media habits and sleep: sleep-friendly screen behavior recommendations for clinicians, educators, and parents. Child Adolesc Psychiatr Clin 27(2):229245. https://doi.org/10.1016/j.chc.2017.11.014

17. Bruni O, Sette S, Fontanesi L, Baiocco R, Laghi F, Baumgartner E (2015) Technology use and sleep quality in preadolescence and adolescence. J Clin Sleep MedJ Clin Sleep Med 11(12):14331441. https://doi.org/10.5664/jcsm.5282

18. Paruthi S, Brooks LJ, D'Ambrosio C, Hall WA, Kotagal S, Lloyd RM, Malow BA, Maski K, Nichols C, Quan SF (2016) Consensus statement of the American Academy of Sleep Medicine on the recommended amount of sleep for healthy children: methodology and discussion. J Clin Sleep Med 12(11):1549-1561. https://doi. org/10.5664/jcsm.5866

19. Blackwell L, Gardiner E, Schoenebeck S (2016) Managing expectations: technology tensions among parents and teens. In: Proceedings of the 19th ACM Conference on Computer-Supported Cooperative Work \& Social Computing. ACM, pp 1390-1401. https://doi.org/10.1145/2818048.2819928

20. Yardi S, Bruckman A (2011) Social and technical challenges in parenting teens' social media use. In: Proceedings of the SIGCHI Conference on Human Factors in Computing Systems. ACM, pp 3237-3246. https://doi.org/10.1145/1978942.1979422

21. Hiniker A, Schoenebeck SY, Kientz JA (2016) Not at the dinner table: parents' and children's perspectives on family technology rules. In: Proceedings of the 19th ACM Conference on ComputerSupported Cooperative Work \& Social Computing. Association for Computing Machinery, pp 1376-1389. https://doi.org/10.1145/ 2818048.2819940

22. Salmela T, Colley A, Häkkilä J (2019) Together in bed?: Couples' mobile technology use in bed. In: Proceedings of the 2019 CHI Conference on Human Factors in Computing Systems. ACM, New York, pp 1-12. https://doi.org/10.1145/3290605.3300732
23. Rooksby J, Rost M, Morrison A, Chalmers MC (2014) Personal tracking as lived informatics. In: Proceedings of the SIGCHI Conference on Human Factors in Computing Systems (CHI 2014). ACM, pp 1163-1172 https://doi.org/10.1145/2556288.2557039

24. Choe EK, Lee NB, Lee B, Pratt W, Kientz JA (2014) Understanding quantified-selfers' practices in collecting and exploring personal data. In: Proceedings of the SIGCHI Conference on Human Factors in Computing Systems (CHI 2014). ACM, New York, pp 1143-1152. https://doi.org/10.1145/2556288.2557372

25. Lee VR, Briggs M (2014) Lessons learned from an initial effort to bring a Quantified Self "meetup" experience to a new demographic. In: Proceedings of the 2014 ACM International Joint Conference on Pervasive and Ubiquitous Computing: Adjunct Publication. ACM, New York, pp 707-710. https://doi.org/10. $1145 / 2638728.2641321$

26. Ravichandran R, Sien S-W, Patel SN, Kientz JA, Pina LR (2017) Making sense of sleep sensors: how sleep sensing technologies support and undermine sleep health. In: CHI 2017. ACM, New York, pp 6864-6875. https://doi.org/10.1145/3025453.3025557

27. Liu W, Ploderer B, Hoang T (2015) In bed with technology: challenges and opportunities for sleep tracking. In: Proceedings of the Annual Meeting of the Australian Special Interest Group for Computer Human Interaction (OzCHI 2015). ACM, New York, pp 142-151. https://doi.org/10.1145/2838739.2838742

28. Liang Z, Ploderer B (2016) Sleep tracking in the real world: a qualitative study into barriers for improving sleep. In: Proceedings of the 28th Australian Conference on Computer-Human Interaction. ACM, New York, pp 537-541. https://doi.org/10. 1145/3010915.3010988

29. Kolla BP, Mansukhani S, Mansukhani MP (2016) Consumer sleep tracking devices: a review of mechanisms, validity and utility. Expert Rev Med Devices 13(5):497-506. https://doi.org/ 10.1586/17434440.2016.1171708

30. Kay M, Choe EK, Shepherd J, Greenstein B, Watson N, Consolvo S, Kientz JA (2012) Lullaby: a capture \& access system for understanding the sleep environment. In: Proceedings of the 2012 ACM Conference on Ubiquitous Computing. ACM, New York, pp 226-234. https://doi.org/10.1145/2370216.2370253

31. Choe EK, Lee B, Kay M, Pratt W, Kientz JA (2015) SleepTight: low-burden, self-monitoring technology for capturing and reflecting on sleep behaviors. In: Proceedings of UbiComp 2015. ACM, New York, pp 121-132. https://doi.org/10.1145/ 2750858.2804266

32. Liang Z, Ploderer B, Liu W, Nagata Y, Bailey J, Kulik L, Li Y (2016) SleepExplorer: a visualization tool to make sense of correlations between personal sleep data and contextual factors. Pers Ubiquit Comput 20(6):985-1000. https://doi.org/10.1007/ s00779-016-0960-6

33. Harper D (2020) Online Etymology Dictionary Retrieved on 12 November 2020, from https://www.etymonline.com/word/refle ct

34. Kolb DA (1984) Experiential learning: experience as the source of learning and development. Prentice-Hall, Englewood Cliffs

35. Argyris C (2002) Double-loop learning, teaching, and research. Acad Manag Learn Educ 1(2):206-218. https://doi.org/10.5465/ amle.2002.8509400

36. Kember D, Leung DYP, Jones A, Loke AY, McKay J, Sinclair K, Tse H, Webb C, Yuet Wong FK, Wong M, Yeung E (2000) Development of a questionnaire to measure the level of reflective thinking. Assess Eval High Educ 25(4):381-395. https://doi.org/ 10.1080/713611442

37. Sengers P, Boehner K, David S, Kaye JJ (2005) Reflective design. In: Proceedings of the 4th decennial conference on Critical computing: between sense and sensibility. Association for Computing Machinery, pp 49-58. https://doi.org/10.1145/1094562.1094569 
38. Baumer EPS (2015) Reflective informatics: conceptual dimensions for designing technologies of reflection. In: Proceedings of the 33rd Annual ACM Conference on Human Factors in Computing Systems. ACM, New York, pp 585-594. https://doi.org/10. $1145 / 2702123.2702234$

39. Choe EK, Lee B, Zhu H, Riche NH, Baur D (2017) Understanding self-reflection: how people reflect on personal data through visual data exploration. In: Proceedings of the 11th EAI International Conference on Pervasive Computing Technologies for Healthcare. ACM, New York, pp 173-182. https://doi.org/10.1145/3154862. 3154881

40. Mols I, Hoven Evd, Eggen B (2020) Everyday life reflection: exploring media interaction with balance, Cogito \& Dott. In: Proceedings of the Fourteenth International Conference on Tangible, Embedded, and Embodied Interaction. ACM, New York, pp 67-79. https://doi.org/10.1145/3374920.3374928

41. Karyda M, Ryöppy M, Buur J, Lucero A (2020) Imagining dataobjects for reflective self-tracking. In: Proceedings of the 2020 CHI Conference on Human Factors in Computing Systems. New York, pp 1-12. https://doi.org/10.1145/3313831.3376844

42. Whooley M, Ploderer B, Gray K (2014) On the integration of selftracking data amongst Quantified Self. In: Proceedings of British HCI 2014. BCS, Southport, UK pp 151-160. https://doi.org/10. 14236/ewic/HCI2014.19

43. Lockton D, Zea-Wolfson T, Chou J, Song YA, Ryan E, Walsh C (2020) Sleep ecologies: tools for snoozy autoethnography. In: Proceedings of the 2020 ACM Designing Interactive Systems Conference (DIS 2020). ACM, New York, pp 1579-1591. https://doi.org/ $10.1145 / 3357236.3395482$

44. Choe EK, Abdullah S, Rabbi M, Thomaz E, Epstein DA, Cordeiro F, Kay M, Abowd GD, Choudhury T, Fogarty J, Lee B, Matthews M, Kientz JA (2017) Semi-automated tracking: a balanced approach for self-monitoring applications. IEEE Pervasive Comput 16(1):74-84. https://doi.org/10.1109/MPRV.2017.18

45. Alfeo AL, Barsocchi P, Cimino MGCA, La Rosa D, Palumbo F, Vaglini G (2018) Sleep behavior assessment via smartwatch and stigmergic receptive fields. Pers Ubiquit Comput 22(2):227-243. https://doi.org/10.1007/s00779-017-1038-9

46. Springer A, Hollis V, Whittaker S (2018) Mood modeling: accuracy depends on active logging and reflection. Pers Ubiquit Comput 22(4):723-737. https://doi.org/10.1007/s00779-018-1123-8

47. Doryab A, Frost M, Faurholt-Jepsen M, Kessing LV, Bardram JE (2015) Impact factor analysis: combining prediction with parameter ranking to reveal the impact of behavior on health outcome. Pers Ubiquit Comput 19(2):355-365. https://doi.org/10.1007/ s00779-014-0826-8

48. Baumer EPS, Khovanskaya V, Matthews M, Reynolds L, Sosik VS, Gay G (2014) Reviewing reflection: on the use of reflection in interactive system design. In: Proceedings of DIS 2014. ACM, New York, pp 93-102. https://doi.org/10.1145/2598510.2598598

49. Eikey EV, Caldeira CM, Figueiredo MC, Chen Y, Borelli JL, Mazmanian M, Zheng K (2021) Beyond self-reflection: introducing the concept of rumination in personal informatics. Pers Ubiquit Comput. https://doi.org/10.1007/s00779-021-01573-w

50. Ploderer B, Reitberger W, Oinas-Kukkonen H, van Gemert-Pijnen $\mathrm{J}$ (2014) Social interaction and reflection for behaviour change. Pers Ubiquit Comput 18(7):1667-1676. https://doi.org/10.1007/ s00779-014-0779-y

51. Saksono H, Castaneda-Sceppa C, Hoffman J, El-Nasr MS, Morris V, Parker AG (2019) Social reflections on fitness tracking data: a study with families in low-SES neighborhoods. In: Proceedings of the 2019 CHI Conference on Human Factors in Computing Systems. ACM, New York, pp 1-14. https://doi.org/10.1145/32906 05.3300543

52. Fleck R, Fitzpatrick G (2010) Reflecting on reflection: framing a design landscape. In: Proceedings of the 22 nd Conference of the
Computer-Human Interaction Special Interest Group of Australia on Computer-Human Interaction. ACM, New York, pp 216-223. https://doi.org/10.1145/1952222.1952269

53. Schön DA (1983) The reflective practitioner: how professionals think in action. Basic Books, New York

54. Slovak P, Frauenberger C, Fitzpatrick G (2017) Reflective practicum: a framework of sensitising concepts to design for transformative reflection. In: Proceedings of the $2017 \mathrm{CHI}$ Conference on Human Factors in Computing Systems. ACM, 3025516, pp 2696-2707. https://doi.org/10.1145/3025453.3025516

55. Yan Y-W, Lin R-M, Su Y-K, Liu M-Y (2018) The relationship between adolescent academic stress and sleep quality: a multiple mediation model. Soc Behav Personal Int J 46(1):63-77. https:// doi.org/10.2224/sbp. 6530

56. Reichert CF, Veitz S, Bühler M, Gruber G, Deuring G, Rehm SS, Rentsch K, Garbazza C, Meyer M, Slawik H, Lin YS, Weibel J (2021) Wide awake at bedtime? Effects of caffeine on sleep and circadian timing in male adolescents - a randomized crossover trial. Biochem Pharmacol 191:114283. https://doi.org/ 10.1016/j.bcp.2020.114283

57. Roux FJ, Kryger MH (2010) Medication effects on sleep. Clin Chest Med 31(2):397-405. https://doi.org/10.1016/j.ccm.2010. 02.008

58. Garcia C, Zhang L, Holt K, Hardeman R, Peterson B (2014) Latina adolescent sleep and mood: an ecological momentary assessment pilot study. J Child Adolesc Psychiatr Nurs 27(3):132-141. https://doi.org/10.1111/jcap.12082

59. Choe EK, Consolvo S, Watson NF, Kientz JA (2011) Opportunities for computing technologies to support healthy sleep behaviors. In: CHI 2011. ACM, 1979395, pp 3053-3062. https://doi. org/10.1145/1978942.1979395

60. Palermo TM, Toliver-Sokol M, Fonareva I, Koh JL (2007) Objective and subjective assessment of sleep in adolescents with chronic pain compared to healthy adolescents. Clin J Pain 23(9):812-820. https://doi.org/10.1097/AJP.0b013e318156ca63

61. Moore M, Meltzer LJ (2008) The sleepy adolescent: causes and consequences of sleepiness in teens. Paediatr Respir Rev 9(2):114-120. https://doi.org/10.1016/j.prrv.2008.01.001 (quiz 120-111)

62. Wolfson AR, Carskadon MA (1998) Sleep schedules and daytime functioning in adolescents. Child Dev 69(4):875-887

63. Tan E, Healey D, Gray AR, Galland BC (2012) Sleep hygiene intervention for youth aged 10 to 18 years with problematic sleep: a before-after pilot study. BMC Pediatr 12:189. https:// doi.org/10.1186/1471-2431-12-189

64. Short MA, Booth SA, Omar O, Ostlundh L, Arora T (2020) The relationship between sleep duration and mood in adolescents: a systematic review and meta-analysis. Sleep Med Rev 52:101311. https://doi.org/10.1016/j.smrv.2020.101311

65. Menghini L, Yuksel D, Goldstone A, Baker FC, de Zambotti M (2021) Performance of Fitbit Charge 3 against polysomnography in measuring sleep in adolescent boys and girls. Chronobiol Int 38(7):1010-1022. https://doi.org/10.1080/07420528.2021. 1903481

66. de Zambotti M, Baker FC, Willoughby AR, Godino JG, Wing D, Patrick K, Colrain IM (2016) Measures of sleep and cardiac functioning during sleep using a multi-sensory commerciallyavailable wristband in adolescents. Physiol Behav 158:143-149. https://doi.org/10.1016/j.physbeh.2016.03.006

67. Hirshkowitz M, Whiton K, Albert SM, Alessi C, Bruni O, DonCarlos L, Hazen N, Herman J, Katz ES, Kheirandish-Gozal L (2015) National Sleep Foundation's sleep time duration recommendations: methodology and results summary. Sleep Health 1(1):40-43. https://doi.org/10.1016/j.sleh.2014.12.010 
68. Holmes AGD (2020) Researcher positionality-a consideration of its influence and place in qualitative research-a new researcher guide. Shanlax Int J Educ 8(4):1-10

69. Lupton D (2016) The Quantified Self: a sociology of self-tracking. Polity, Cambridge

70. Braun V, Clarke V (2006) Using thematic analysis in psychology. Qual Res Psychol 3(2):77-101. https://doi.org/10.1191/ 1478088706qp063oa

71. McCutcheon D, Nelson J, Maxwell J, Nash T, de Sousa M (2013) Adolescence: boundaries and connections: an RCN guide for working with young people. (Manual) Royal College of Nursing, London. https://eprints.kingston.ac.uk/id/eprint/ 30304.

72. Lee MK, Kim J, Forlizzi J, Kiesler S (2015) Personalization revisited: a reflective approach helps people better personalize health services and motivates them to increase physical activity. In: Proceedings of the 2015 ACM International Joint Conference on Pervasive and Ubiquitous Computing. Association for Computing Machinery, pp 743-754. https://doi.org/10.1145/ 2750858.2807552

73. Chung C-F, Agapie E, Schroeder J, Mishra S, Fogarty J, Munson SA (2017) When personal tracking becomes social: examining the use of instagram for healthy eating. In: Proceedings of the 2017 CHI Conference on Human Factors in Computing Systems. ACM, 3025747, pp 1674-1687. https://doi.org/10.1145/3025453.30257 47

74. Altman I (1977) Privacy regulation: culturally universal or culturally specific? J Soc Issues 33(3):66-84. https://doi.org/10.1111/j. 1540-4560.1977.tb01883.x

75. Karkar R, Schroeder J, Epstein DA, Pina LR, Scofield J, Fogarty J, Kientz JA, Munson SA, Vilardaga R, Zia J (2017) TummyTrials: a feasibility study of using self-experimentation to detect individualized food triggers. In: Proceedings of the 2017 CHI Conference on Human Factors in Computing Systems. Association for Computing Machinery, pp 6850-6863. https://doi.org/10.1145/30254 53.3025480

76. Dewar B, Mackay R, Smith S, Pullin S, Tocher R (2010) Use of emotional touchpoints as a method of tapping into the experience of receiving compassionate care in a hospital setting. J Res Nurs 15(1):29-41. https://doi.org/10.1177/1744987109352932

77. Hudson W (2012) Card sorting. Interaction Design Foundation. Retrieved on from https://www.interaction-design.org/literature/ book/the-encyclopedia-of-human-computer-interaction-2nd-ed/ card-sorting

78. Mackay WE (2004) The interactive thread: exploring methods for multi-disciplinary design. In: Proceedings of the 5th conference on Designing interactive systems: processes, practices, methods, and techniques. Association for Computing Machinery, pp 103112. https://doi.org/10.1145/1013115.1013131

79. Halskov K, Dalsgård P (2006) Inspiration card workshops. In: Proceedings of the 6th conference on Designing Interactive systems. ACM, New York, pp 2-11. https://doi.org/10.1145/11424 05.1142409

80. Friedman B, Hendry D (2012) The envisioning cards: a toolkit for catalyzing humanistic and technical imaginations. In: Proceedings of the SIGCHI Conference on Human Factors in Computing Systems. ACM, New York, pp 1145-1148. https://doi.org/10.1145/ 2207676.2208562

81. Colusso L, Do T, Hsieh G (2018) Behavior change design sprints. In: Proceedings of the 2018 Designing Interactive Systems Conference. Association for Computing Machinery, pp 791-803. https://doi.org/10.1145/3196709.3196739

82. Lucero A, Holopainen J, Ollila E, Suomela R, Karapanos E (2013) The playful experiences (PLEX) framework as a guide for expert evaluation. In: Proceedings of the 6th International Conference on Designing Pleasurable Products and Interfaces. Association for Computing Machinery, pp 221-230. https://doi.org/10.1145/ 2513506.2513530

83. Wolever RQ, Dreusicke M, Fikkan J, Hawkins TV, Yeung S, Wakefield J, Duda L, Flowers P, Cook C, Skinner E (2010) Integrative health coaching for patients with type 2 diabetes. Diabetes Educ 36(4):629-639. https://doi.org/10.1177/0145721710371523

84. Olsen JM, Nesbitt BJ (2010) Health coaching to improve healthy lifestyle behaviors: an integrative review. Am J Health Promot 25(1):e1-e12. https://doi.org/10.4278/ajhp.090313-LIT-101

85. Kocielnik R, Xiao L, Avrahami D, Hsieh G (2018) Reflection companion: a conversational system for engaging users in reflection on physical activity. Proc ACM Interact Mob Wearable Ubiquitous Technol 2(2):Article 70. https://doi.org/10.1145/3214273

86. Potapov K, Vasalou A, Lee V, Marshall P (2021) What do teens make of personal informatics? Young people's responses to selftracking practices for self-determined motives. In: Proceedings of the $2021 \mathrm{CHI}$ Conference on Human Factors in Computing Systems. Association for Computing Machinery, p Article 356. https://doi.org/10.1145/3411764.3445239

87. Fleck R, Cecchinato ME, Cox AL, Harrison D, Marshall P, Na JH, Skatova A (2020) Life-swap: how discussions around personal data can motivate desire for change. Pers Ubiquit Comput 24:669-681. https://doi.org/10.1007/s00779-020-01372-9

88. Kocielnik R, Avrahami D, Marlow J, Lu D, Hsieh G (2018) Designing for workplace reflection: a chat and voice-based conversational agent. In: Proceedings of the 2018 Designing Interactive Systems Conference. Association for Computing Machinery, pp 881-894. https://doi.org/10.1145/3196709.3196784

89. Suchman L (1993) Working relations of technology production and use. Comput Support Coop Work 2(1):21-39. https://doi.org/ 10.1007/BF00749282

90. Buckingham D (2007) Introducing identity. In: Buckingham D (ed) Youth, identity, and digital media. The John D. and Catherine T. MacArthur Foundation Series on Digital Media and Learning. MIT Press, Cambridge, pp 1-22

91. Coleman JC (2011) The nature of adolescence, 4th edn. Routledge, London

92. Palen L, Dourish P (2003) Unpacking "privacy" for a networked world. In: Proceedings of the SIGCHI Conference on Human Factors in Computing Systems. ACM, New York, pp 129-136. https:// doi.org/10.1145/642611.642635

93. Bentley F, Tollmar K, Stephenson P, Levy L, Jones B, Robertson S, Price E, Catrambone R, Wilson J (2013) Health mashups: presenting statistical patterns between wellbeing data and context in natural language to promote behavior change. ACM Trans Comput-Hum Interact 20(5):Article 30. https://doi.org/10.1145/ 2503823

94. Caine K (2016) Local standards for sample size at CHI. In: Proceedings of the SIGCHI Conference on Human Factors in Computing Systems (CHI 2016). ACM, New York, pp 981-992. https://doi.org/10.1145/2858036.2858498

95. Ibáñez V, Silva J, Cauli O (2018) A survey on sleep assessment methods. PeerJ 6:e4849. https://doi.org/10.7717/peerj.4849

96. Harvey AG, Tang NKY (2012) (Mis)perception of sleep in insomnia: a puzzle and a resolution. Psychol Bull 138(1):77-101. https://doi.org/10.1037/a0025730

97. Lund HG, Rybarczyk BD, Perrin PB, Leszczyszyn D, Stepanski E (2013) The discrepancy between subjective and objective measures of sleep in older adults receiving CBT for comorbid insomnia. J Clin Psychol 69(10):1108-1120. https://doi.org/10. 1002/jclp. 21938

Publisher's note Springer Nature remains neutral with regard to jurisdictional claims in published maps and institutional affiliations. 